\title{
WATCH OUT FOR
}
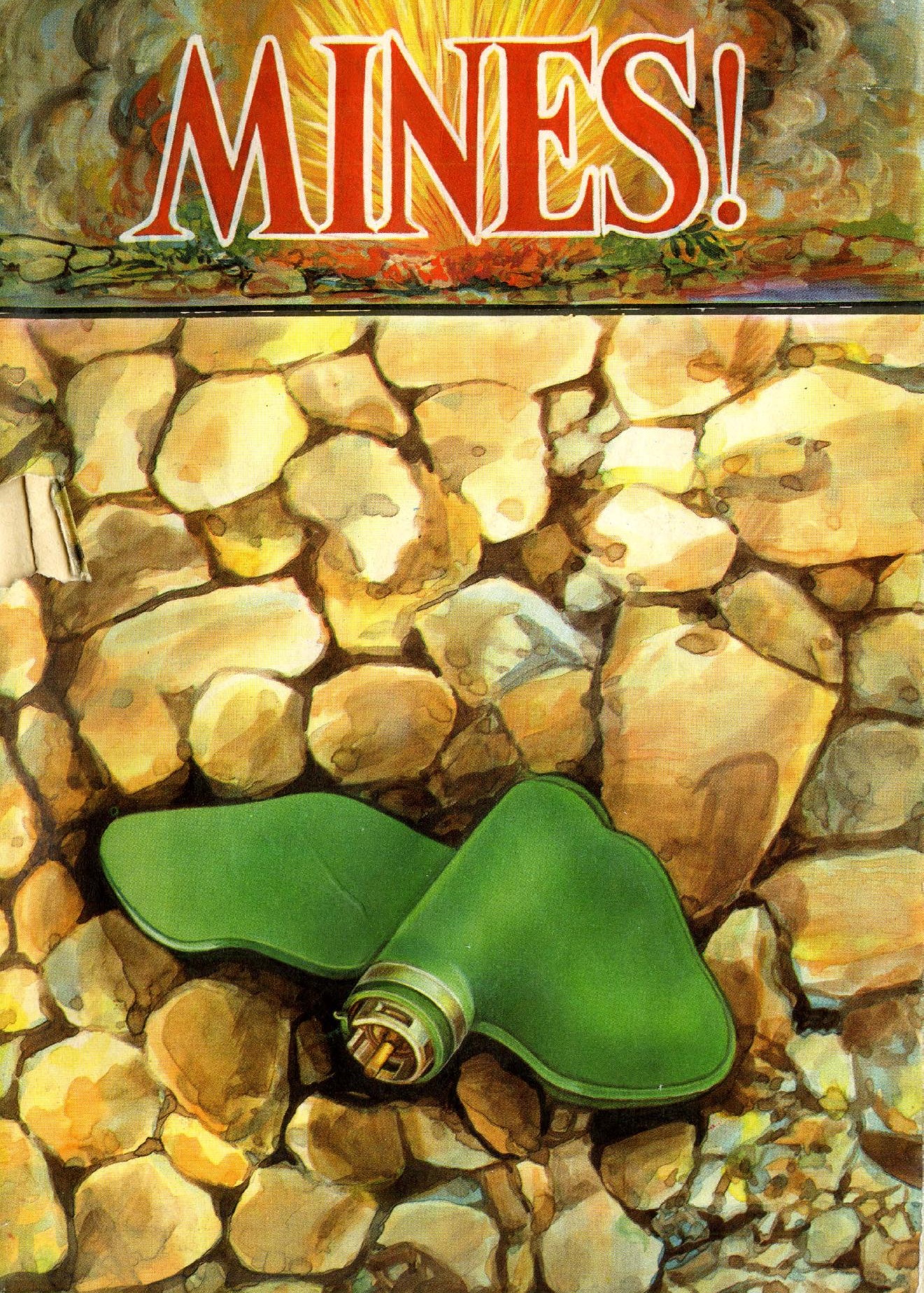


\title{
Watch out for
}

\section{Mines!}

\author{
Prepared by SERVE
}

Year $1989-1,000^{\circ}$ copies

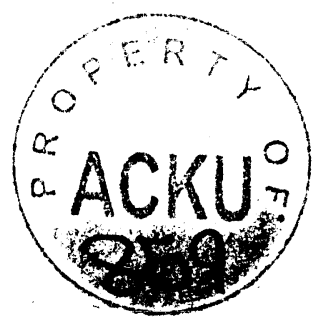



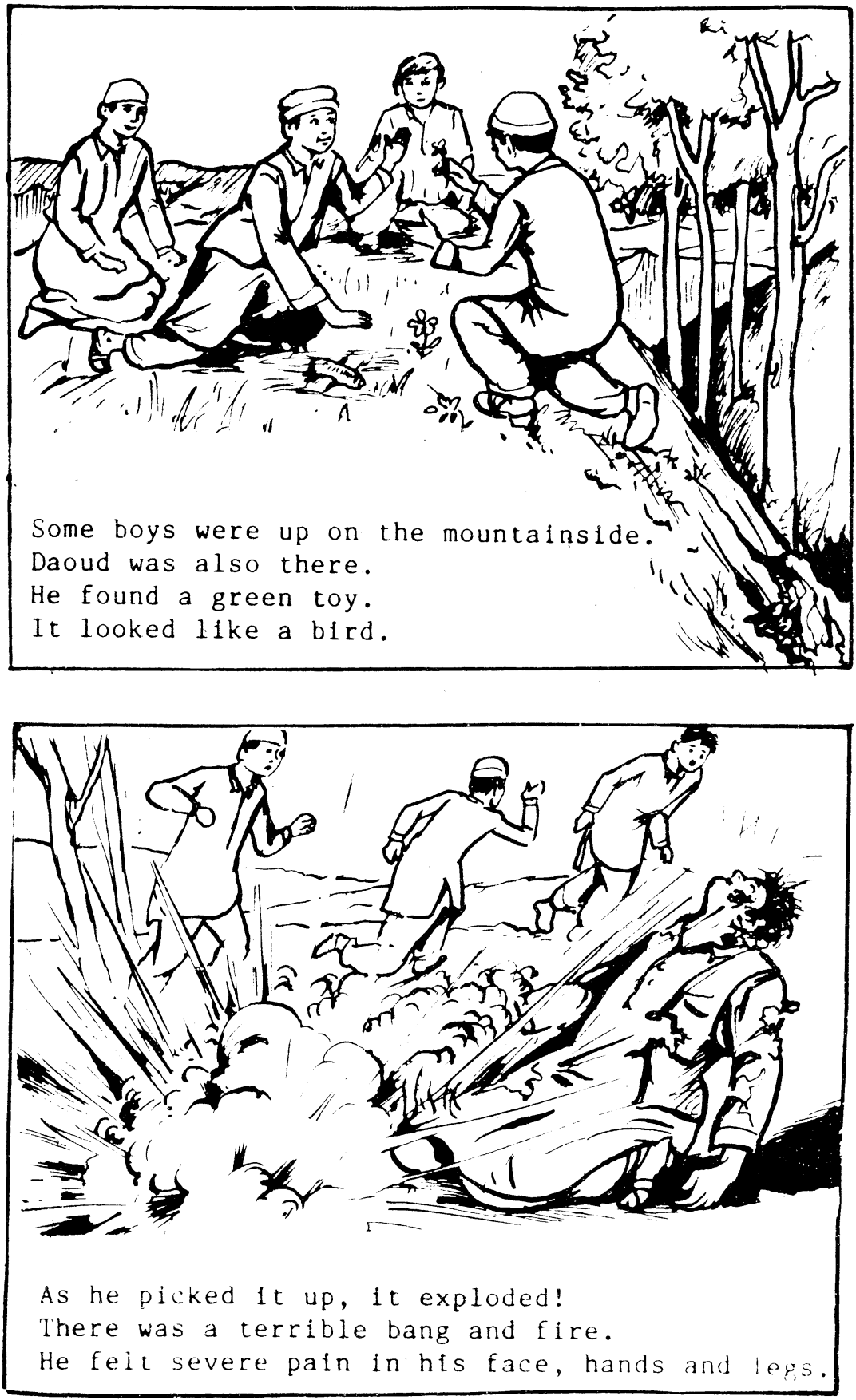

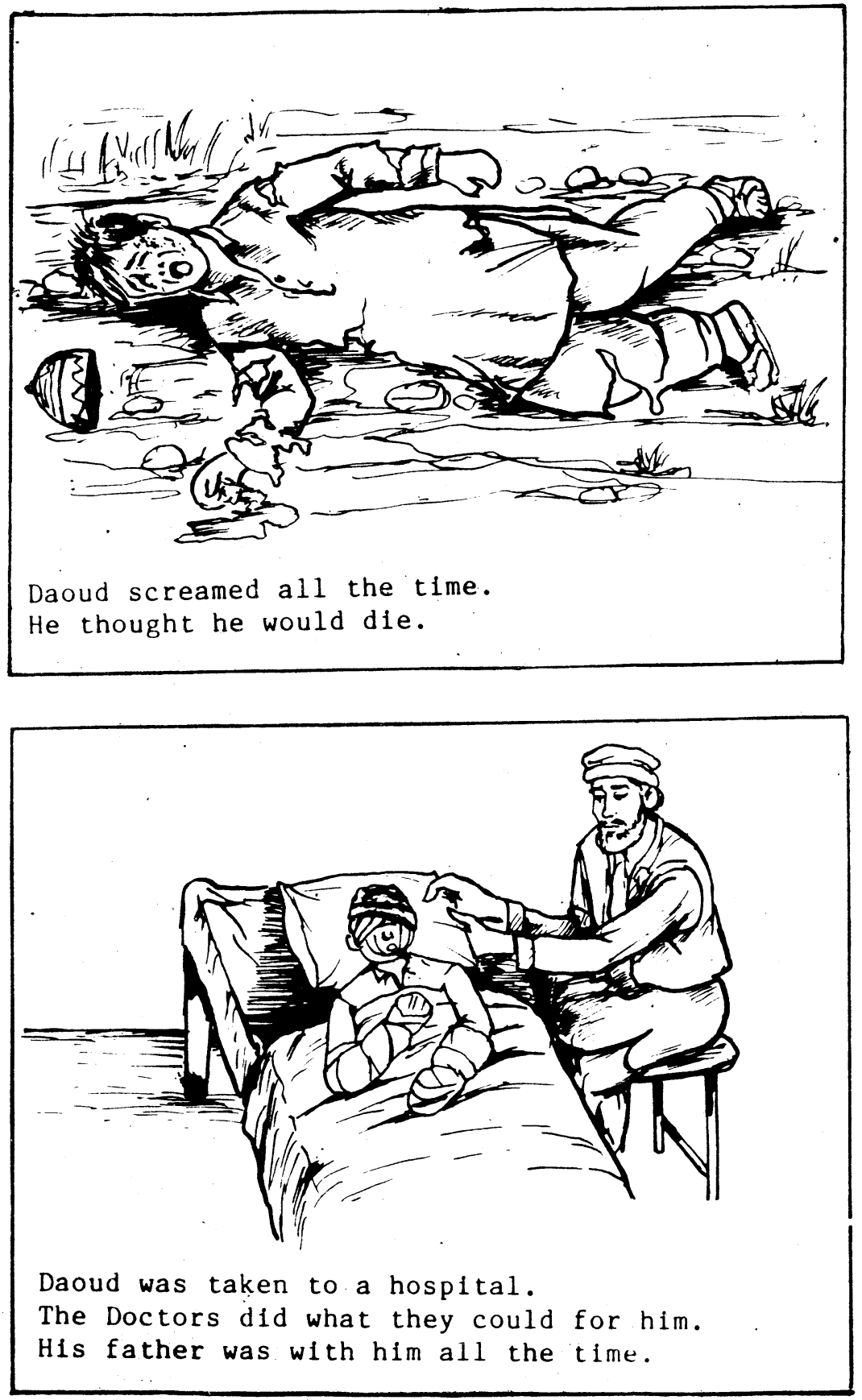


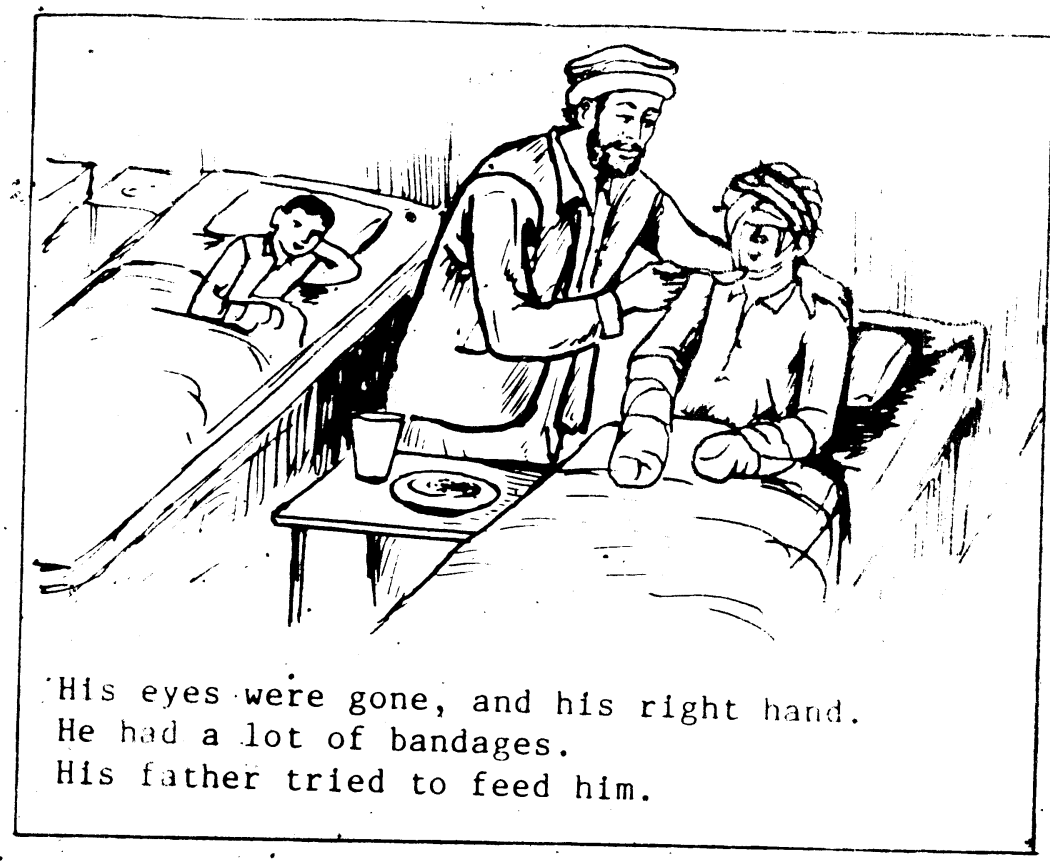

Daoud told his father how it happened.

"It was such a nice green bird.

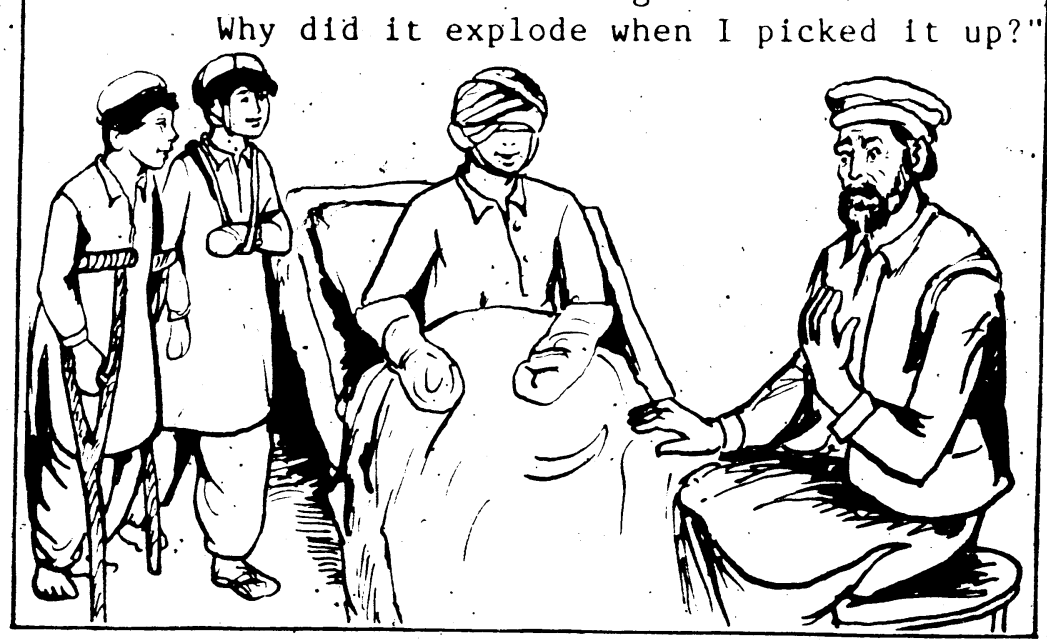



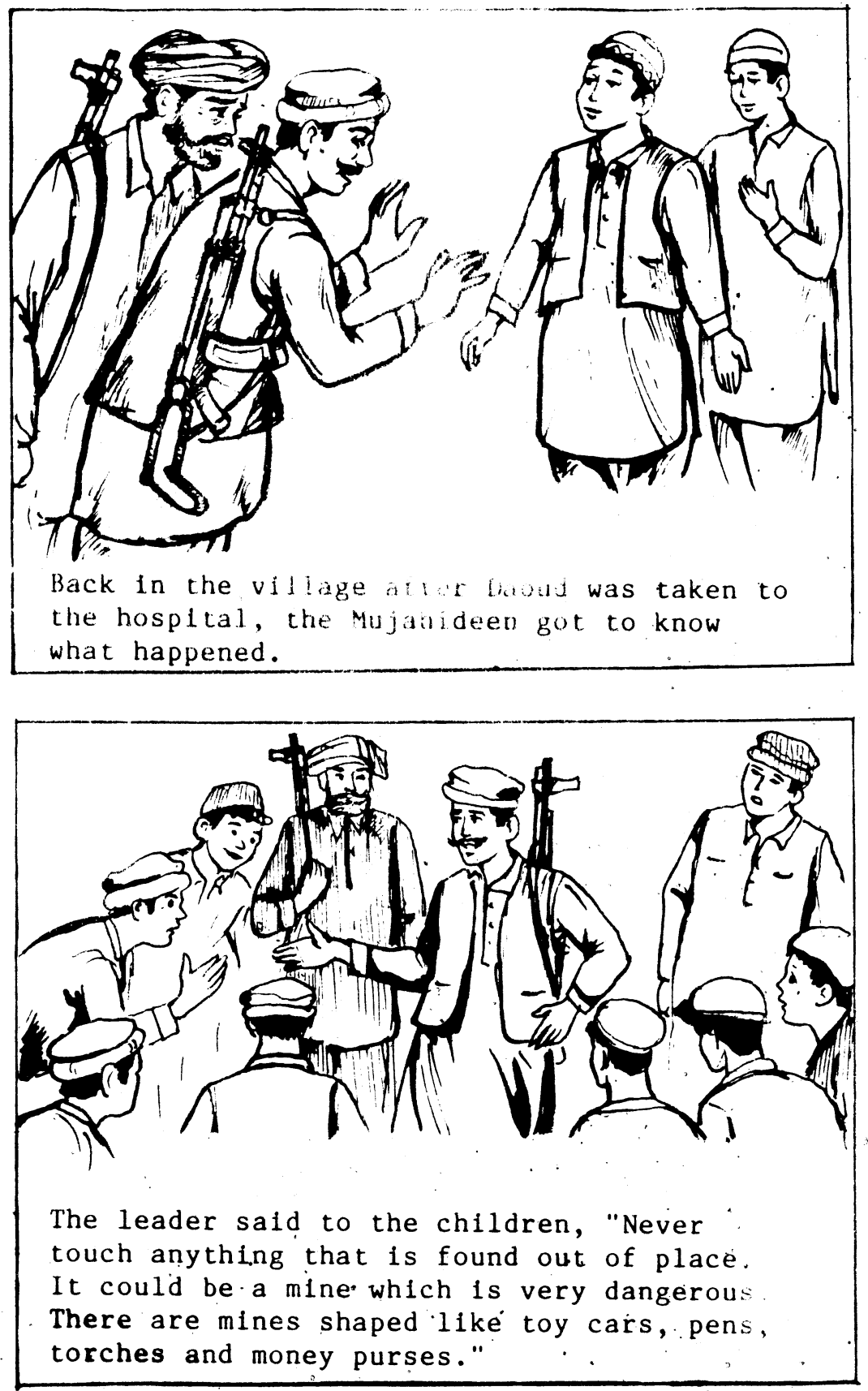
6
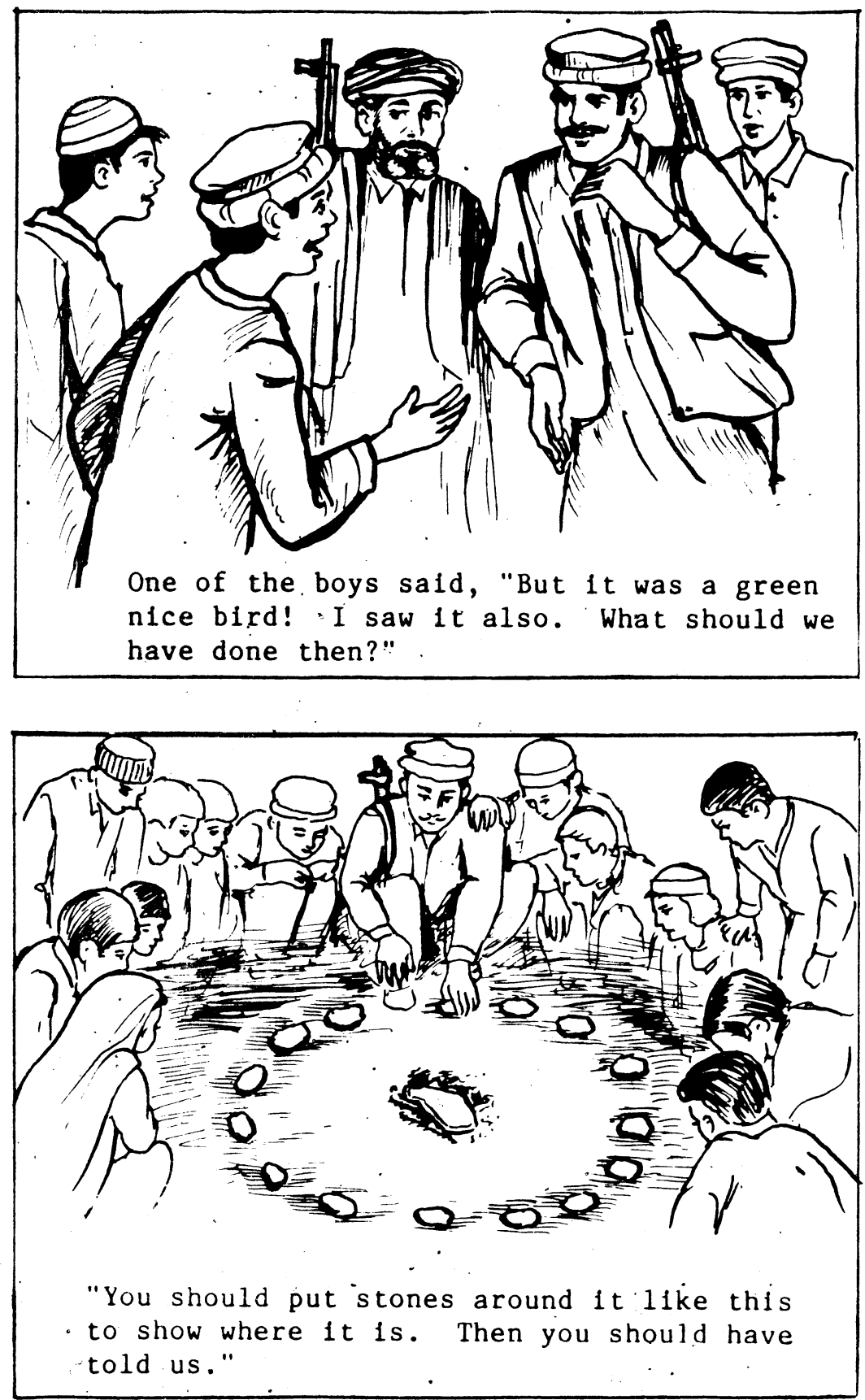
NADIR
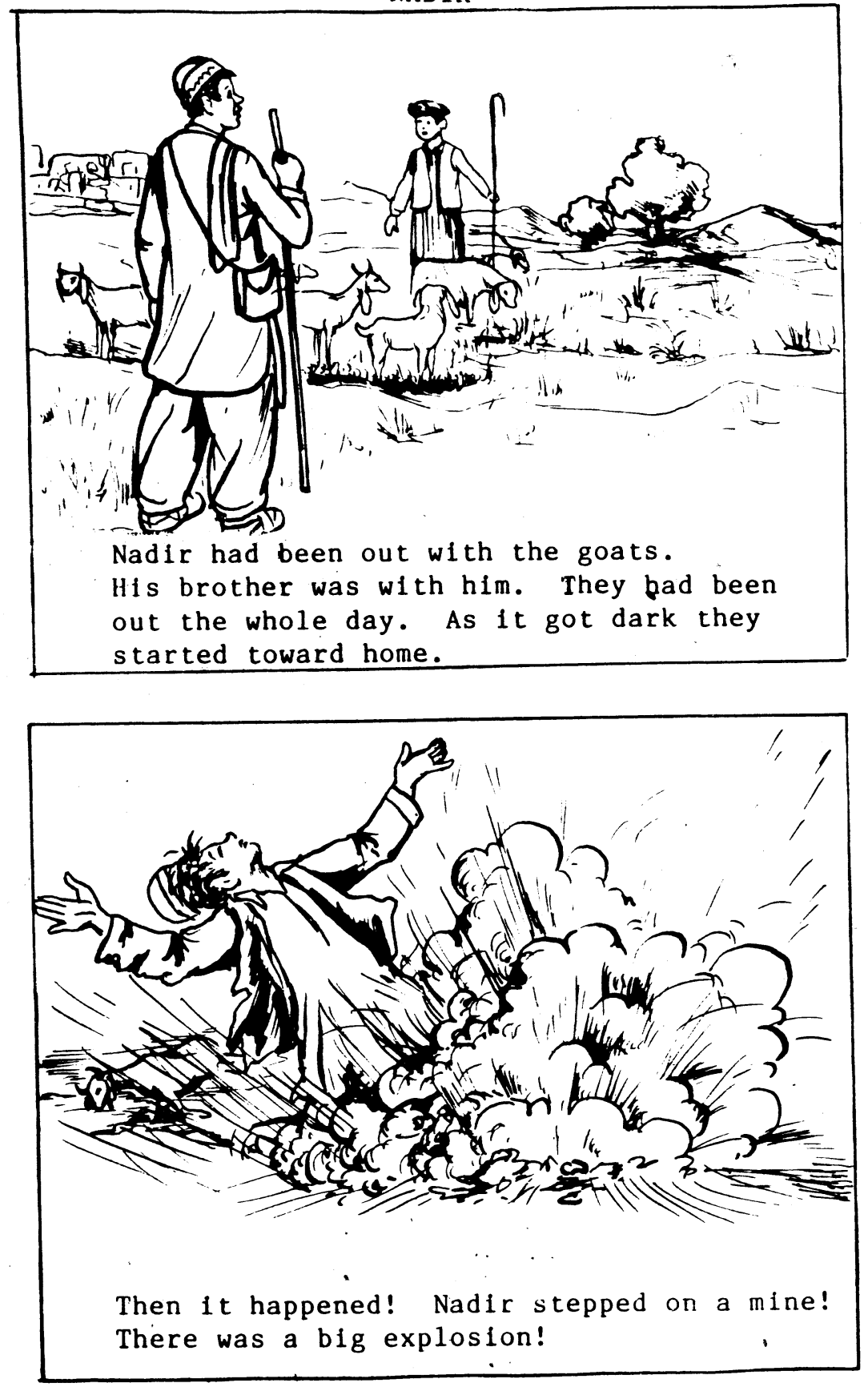
8
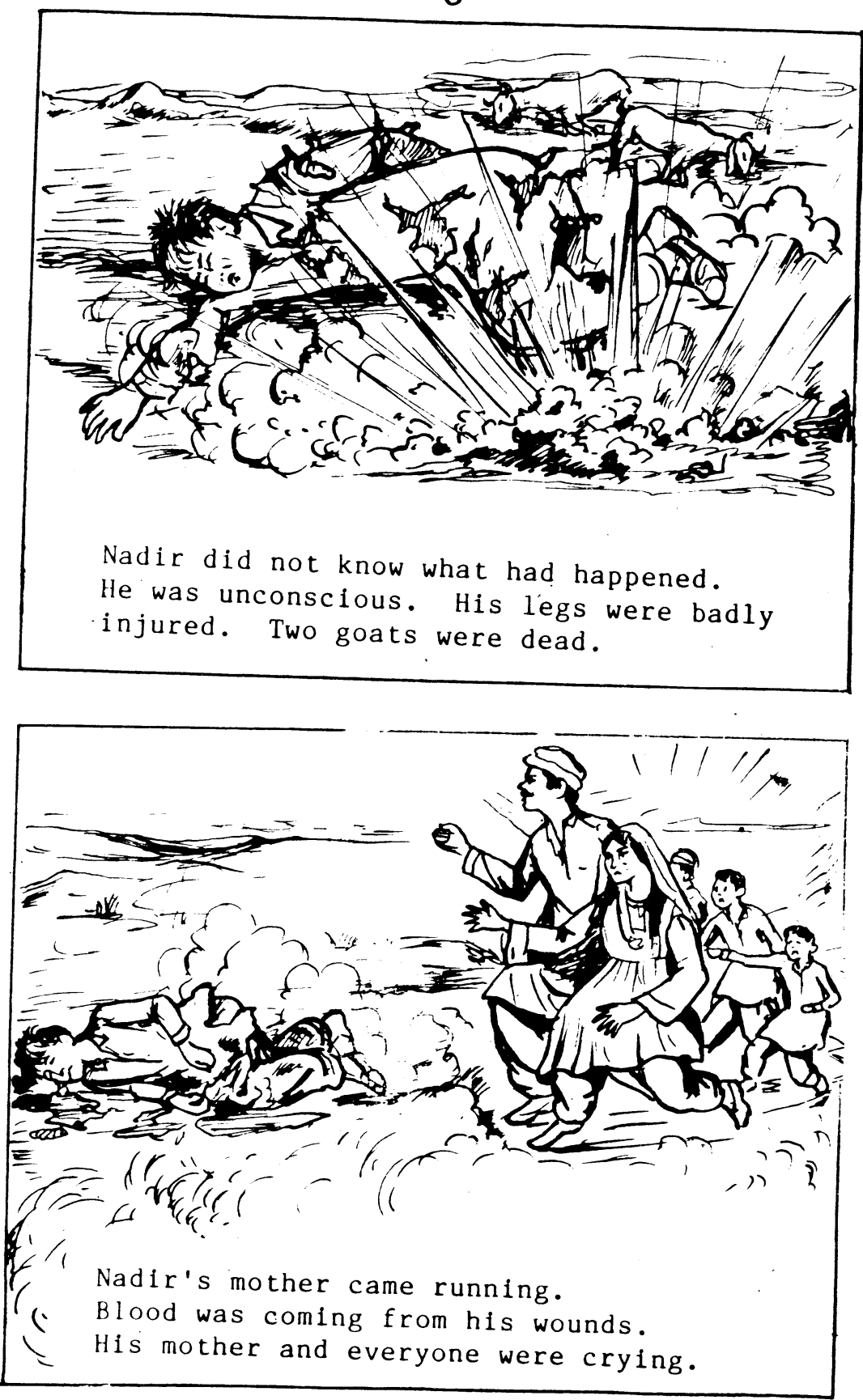
9
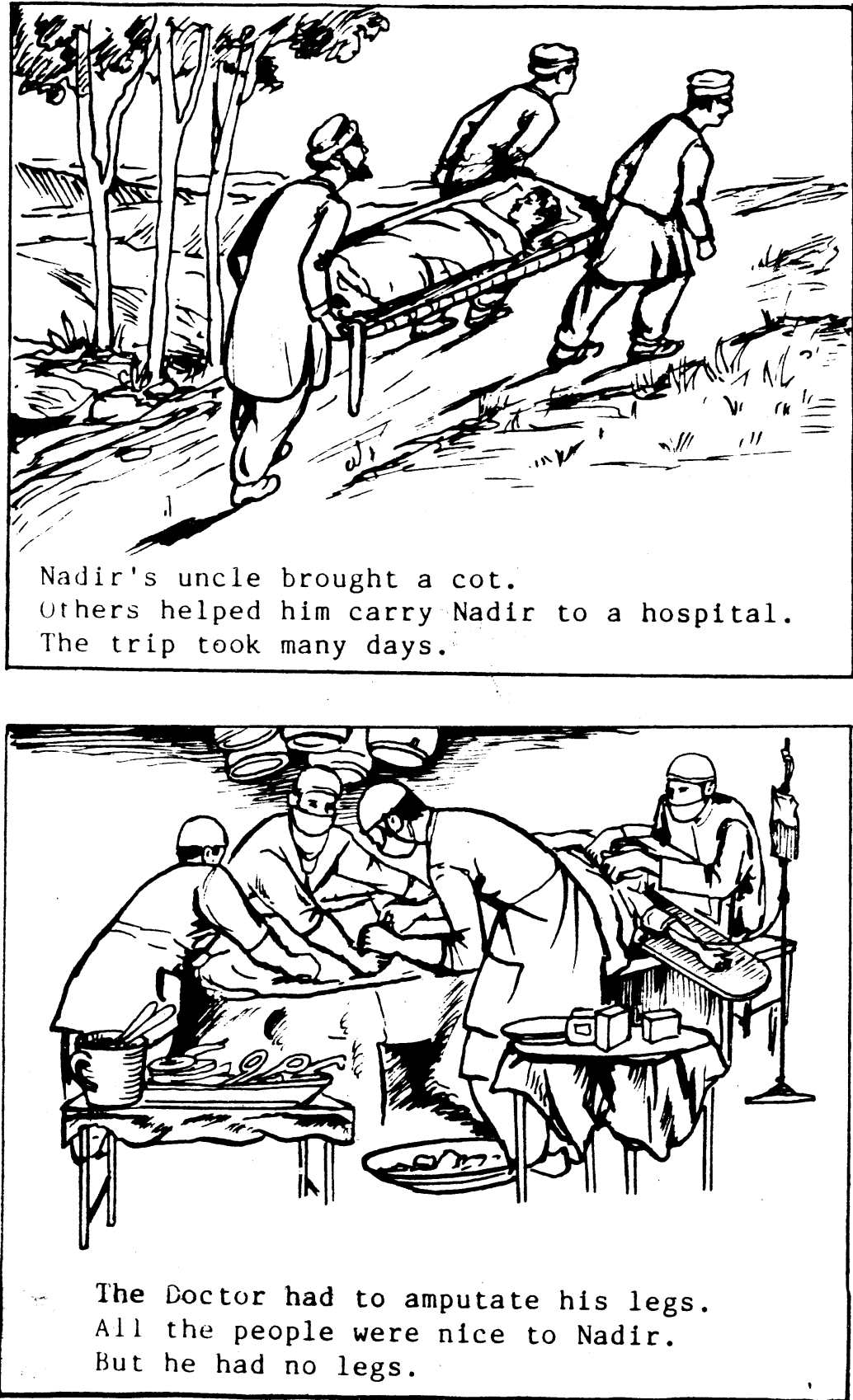
10
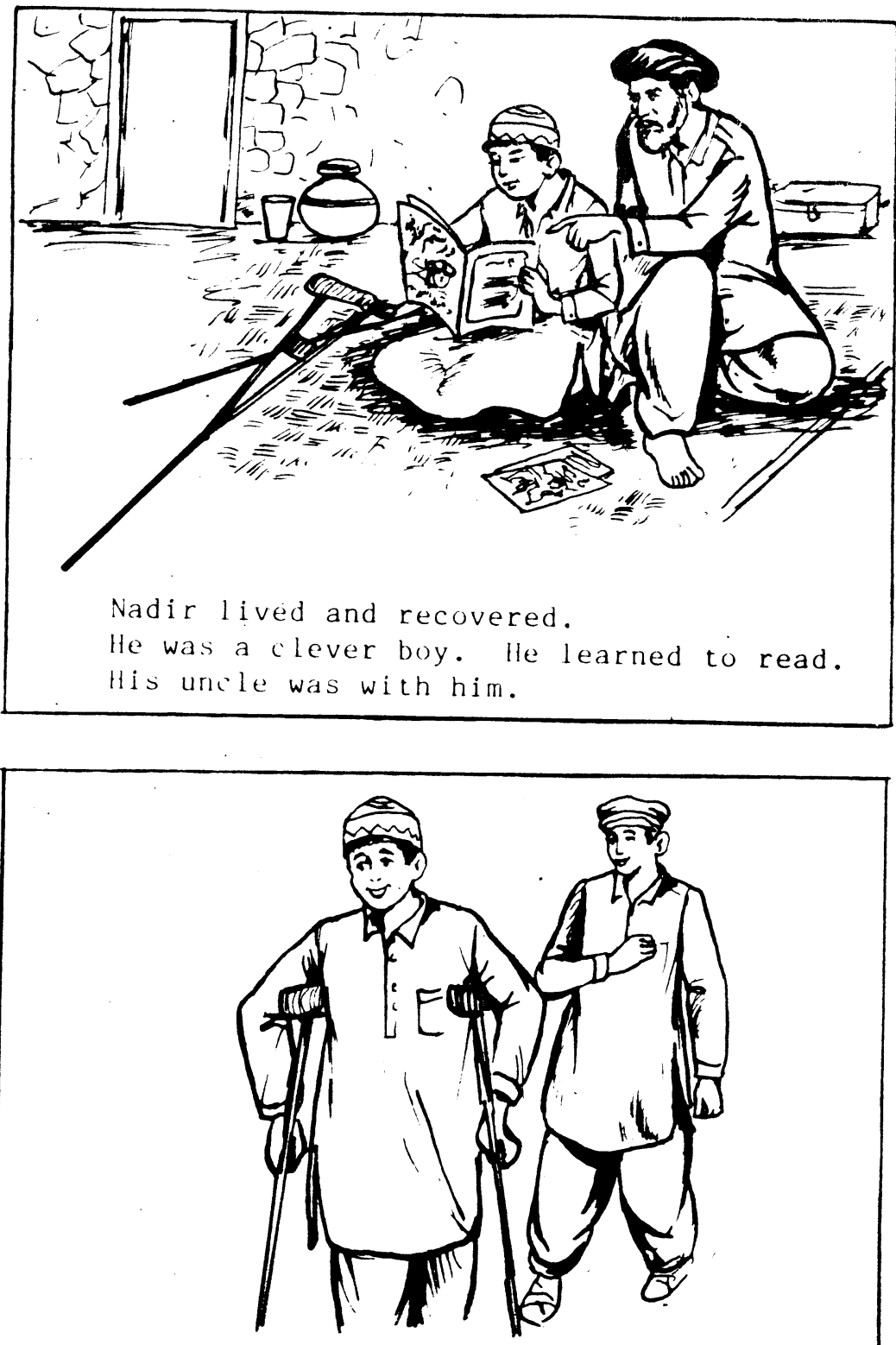

The wounds healed.

Then he got prostheses and crutches. He could move about a little with them. 


\section{The Lord}

\section{is my Shepherd}

The Lord is my shepherd, I shall not be in want.

He restores my soul.

He guides me in paths of righteousness for His name's sake.

Even though I walk through

The valley of the shadow of death,

I will fear no evil,

For you are with me; 
Your rod and Your staff, they comfort me.

You prepare a table before me in the presence of my enemies.

You anoint my head with oil; my cup overflows.

Surely goodness and love will follow me all the days of my life.

And I will dwell in the house of the Lord forever.

-The Prophet Daoud 


\section{3}

MAHMOOD
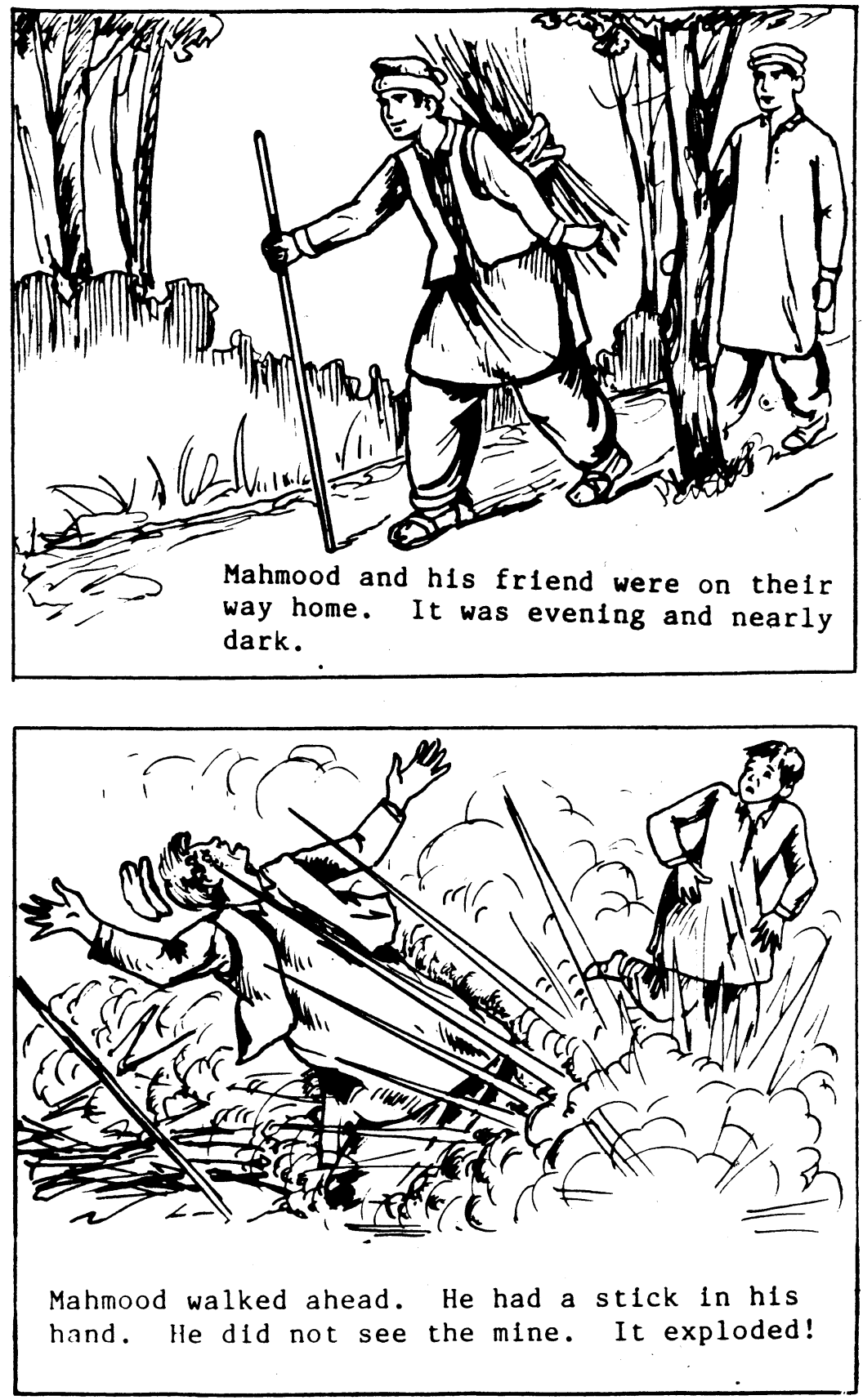

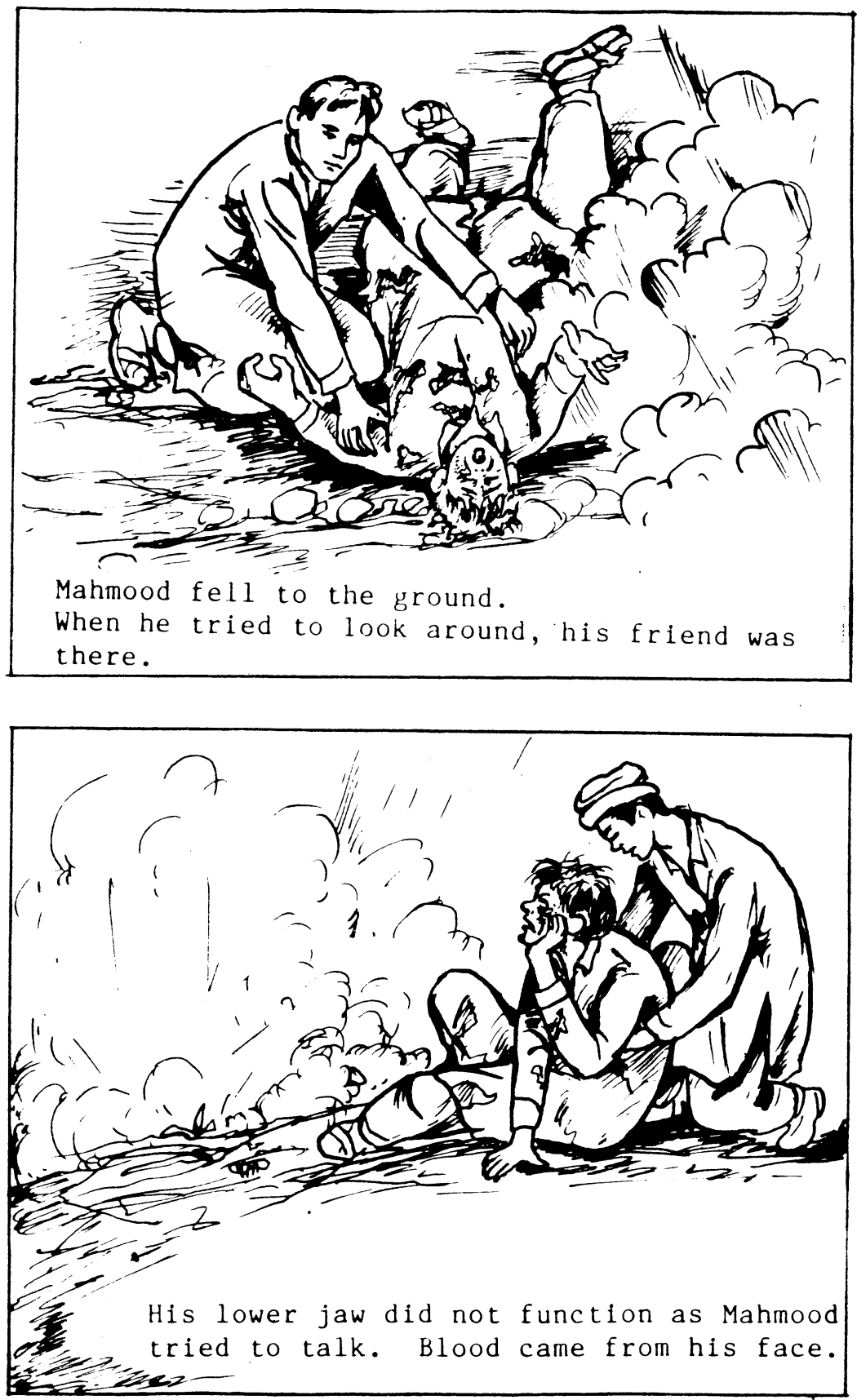

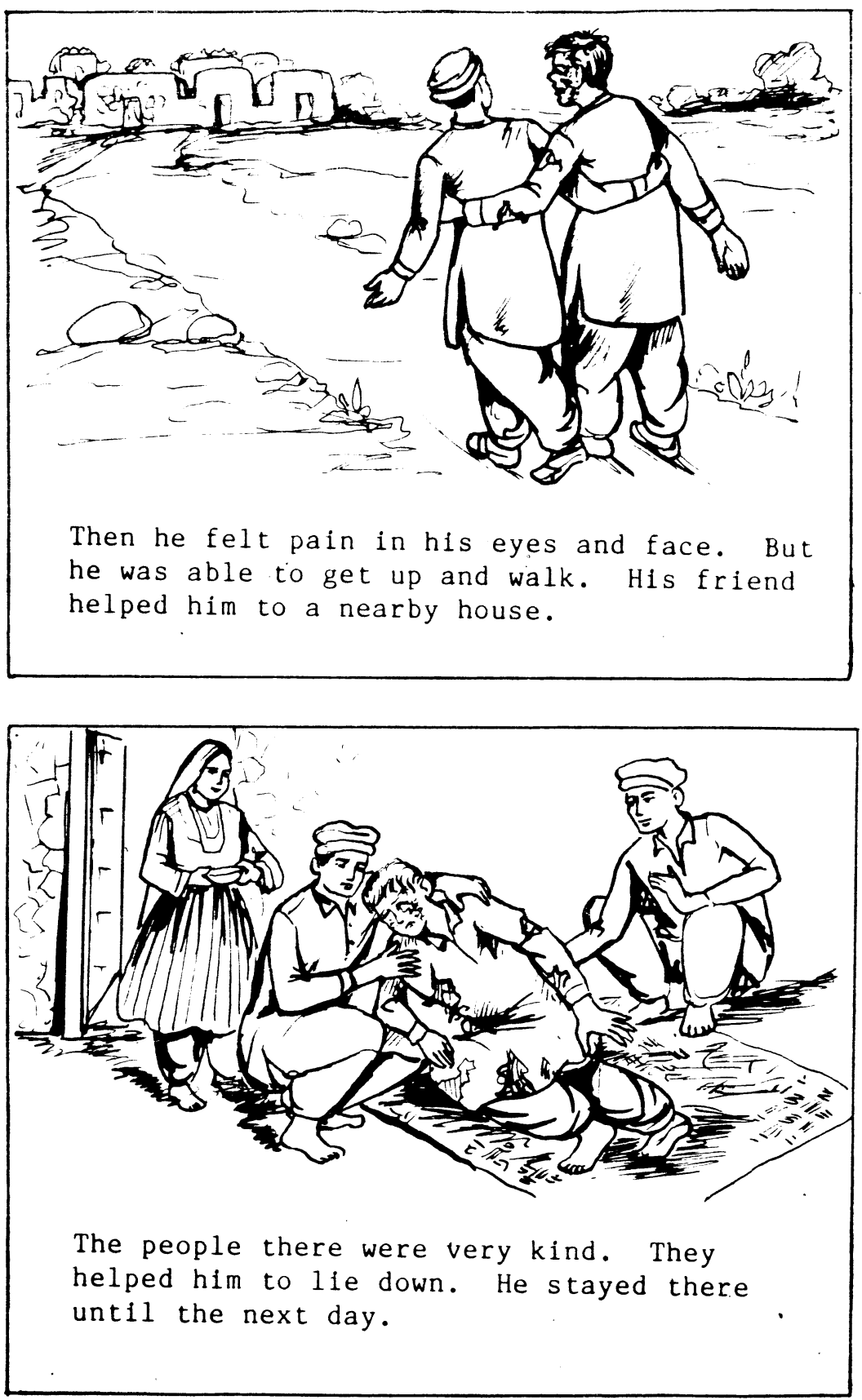
16
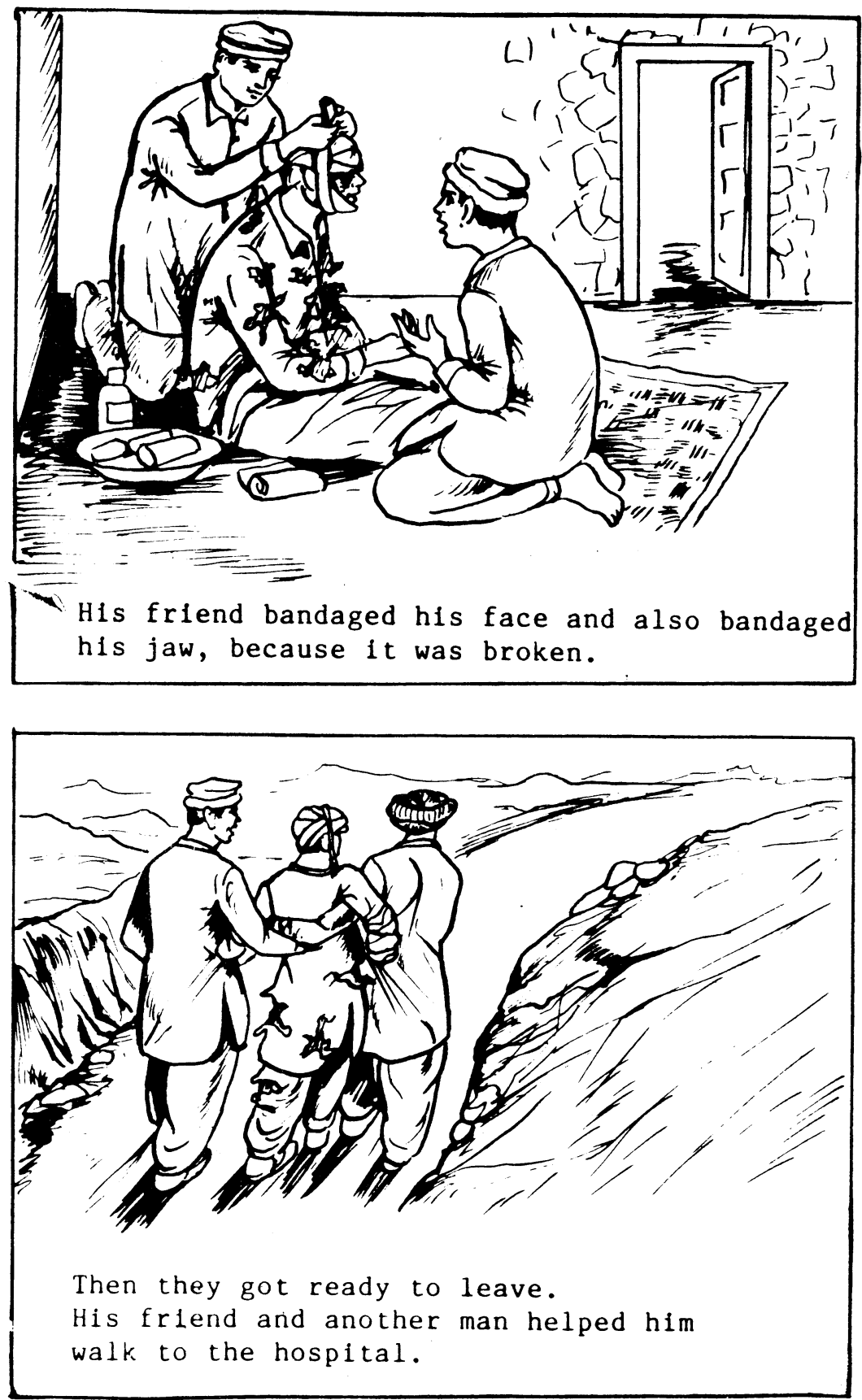

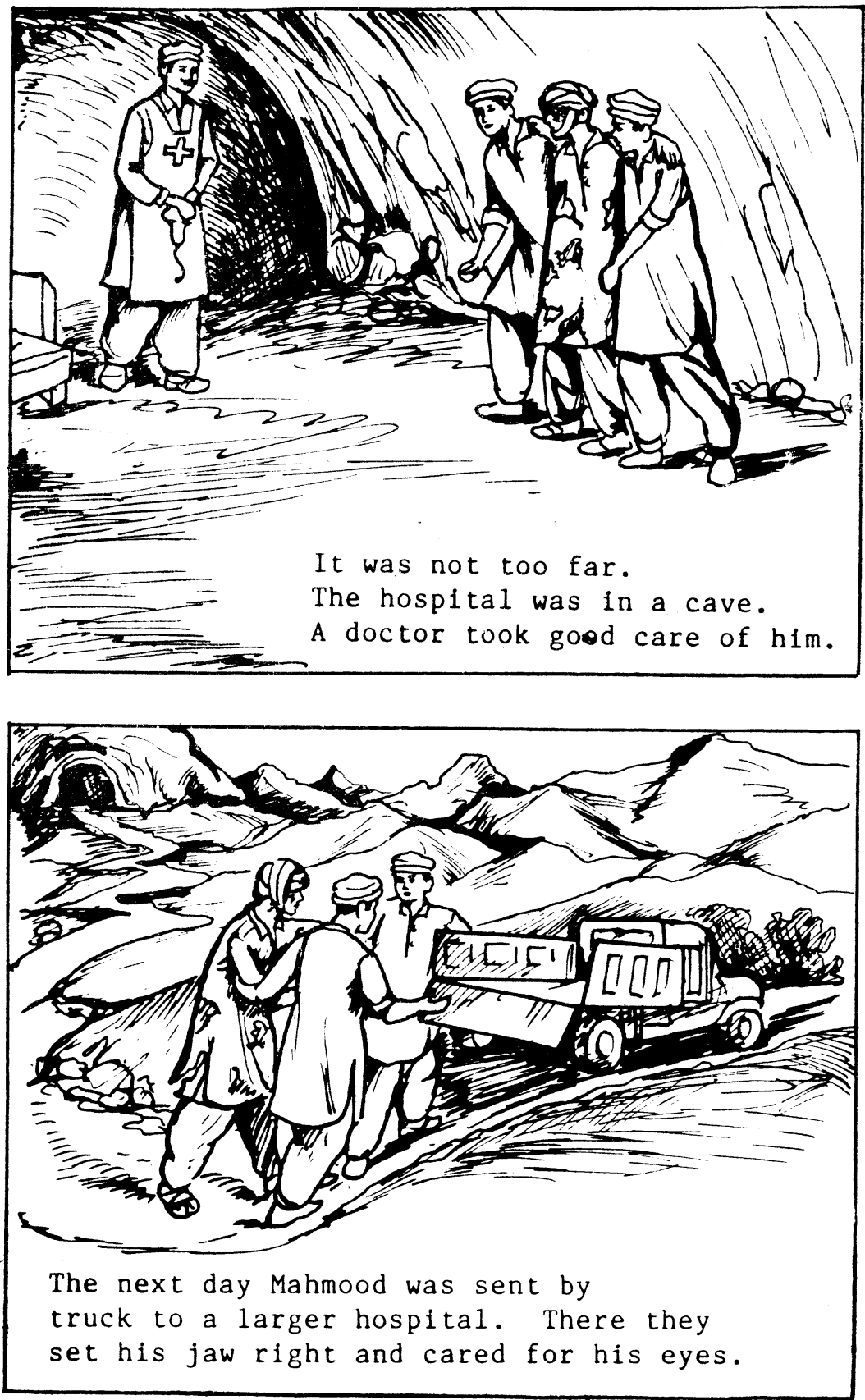


\section{A National Anthem}

This is the apple of our eyes, And the light of our hearts, This is the sign of our honour, This is our life forever. This is our reputation and national pride. It is sweeter to us than all the world. It is higher than the lofty sky. This is our Afghanistan. This is our Afghanistan.

Bravery is our occupation, Our sacrifice, our standard. Independence is our habit. Guarding our country is our dignity. Honour and zeal are our pride: Afghan's forever Keep their heads high in the world. This is our Afghanistan. This is our Afghanistan. 

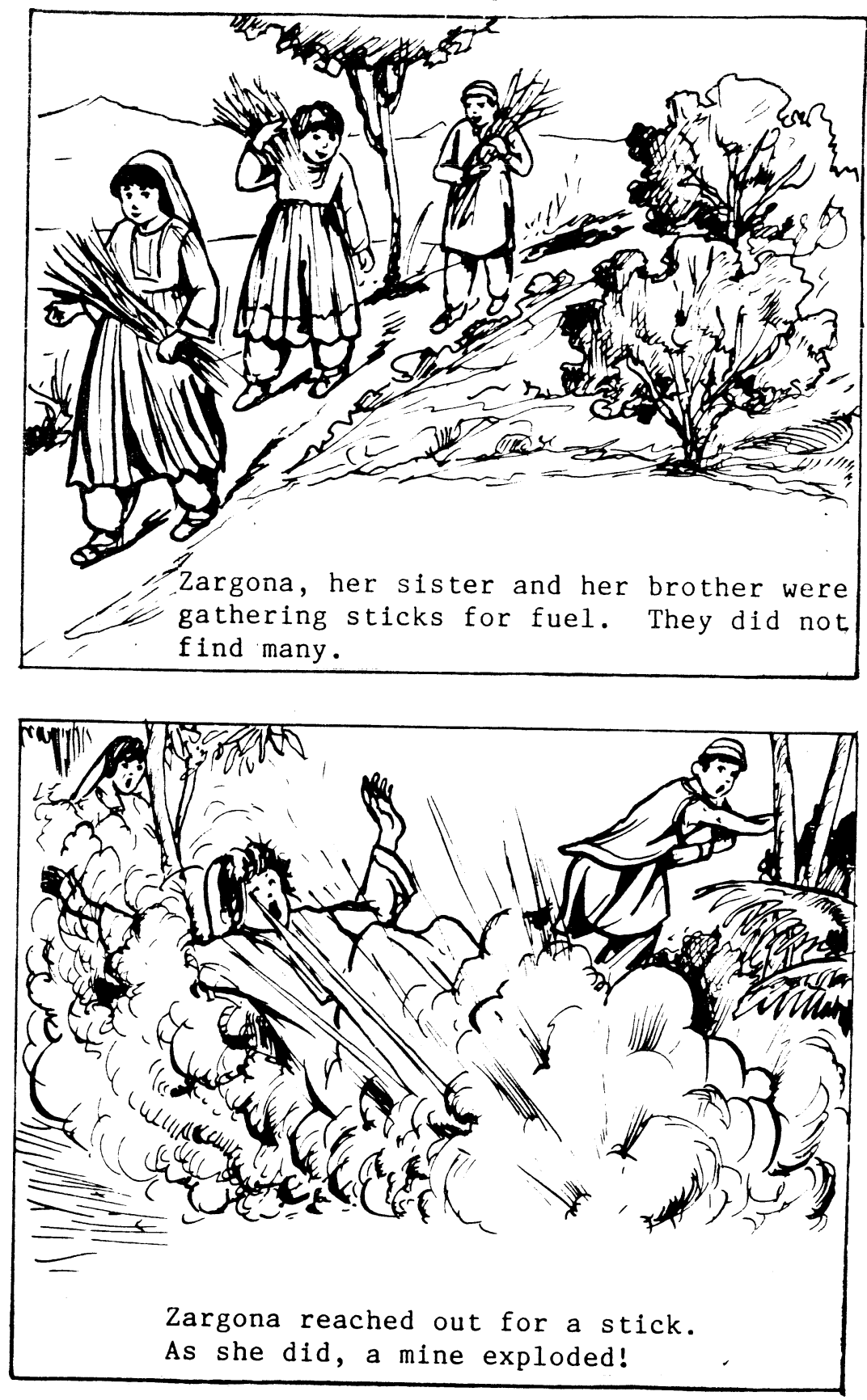

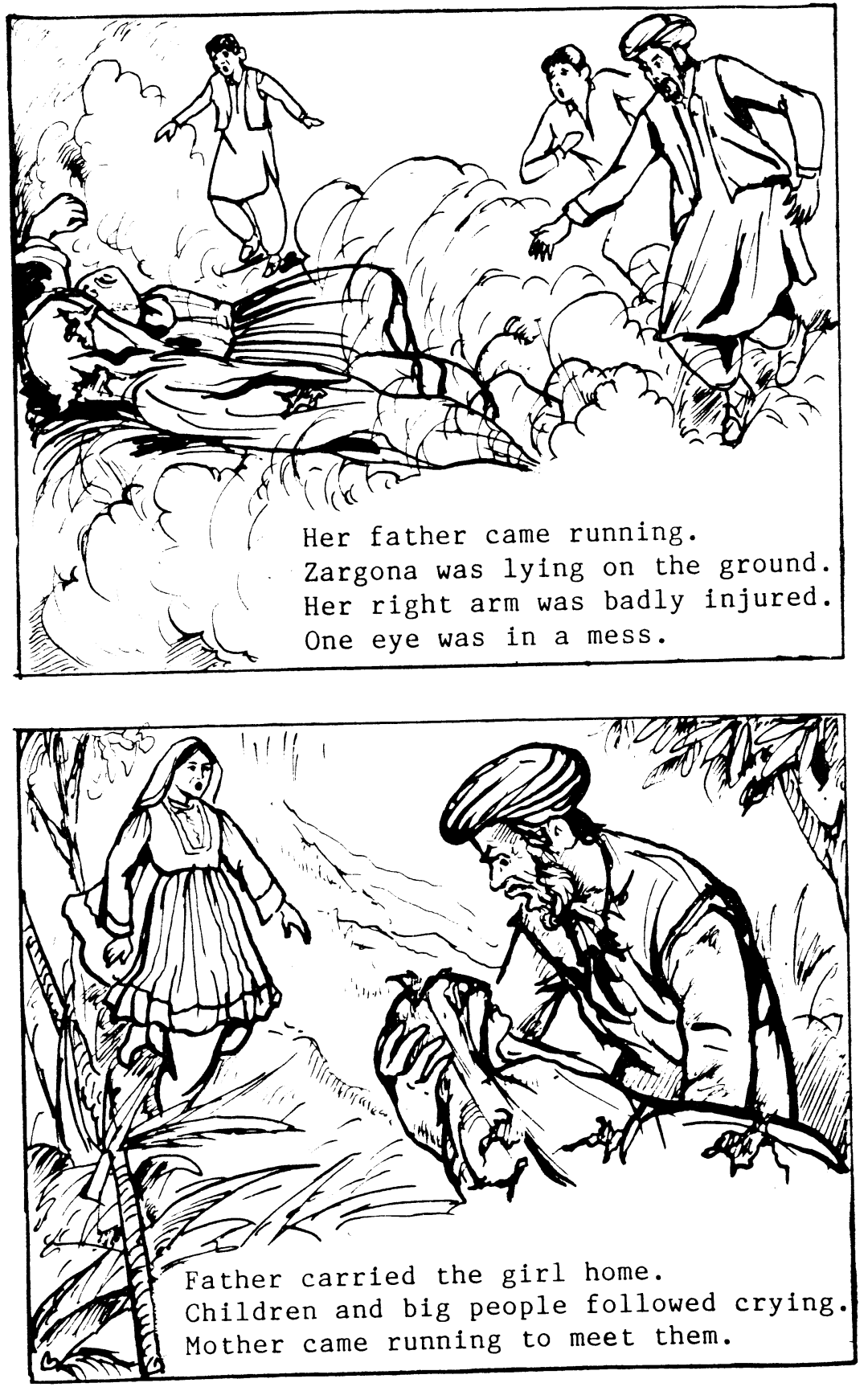
Zargona was taken to the hospital.
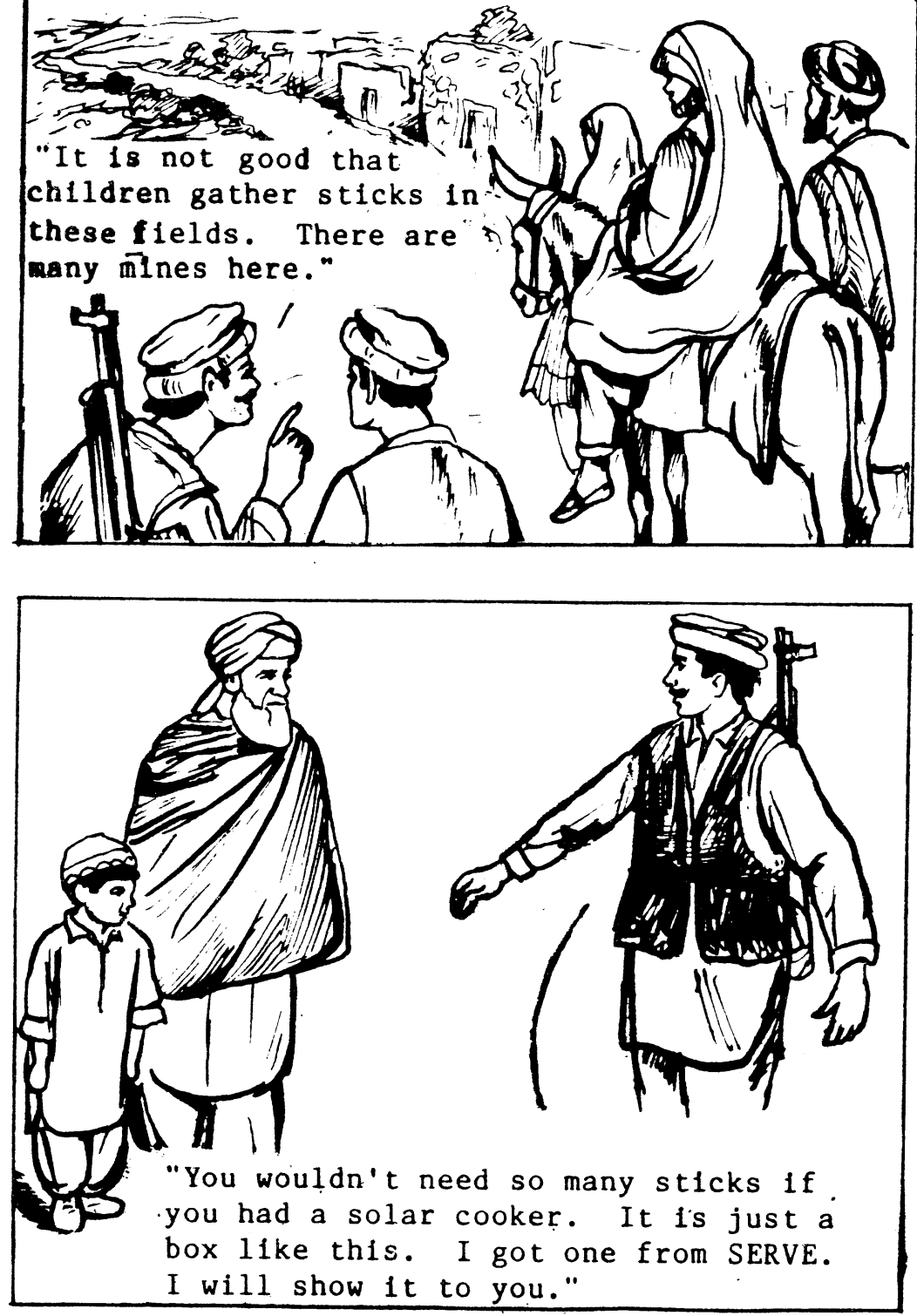

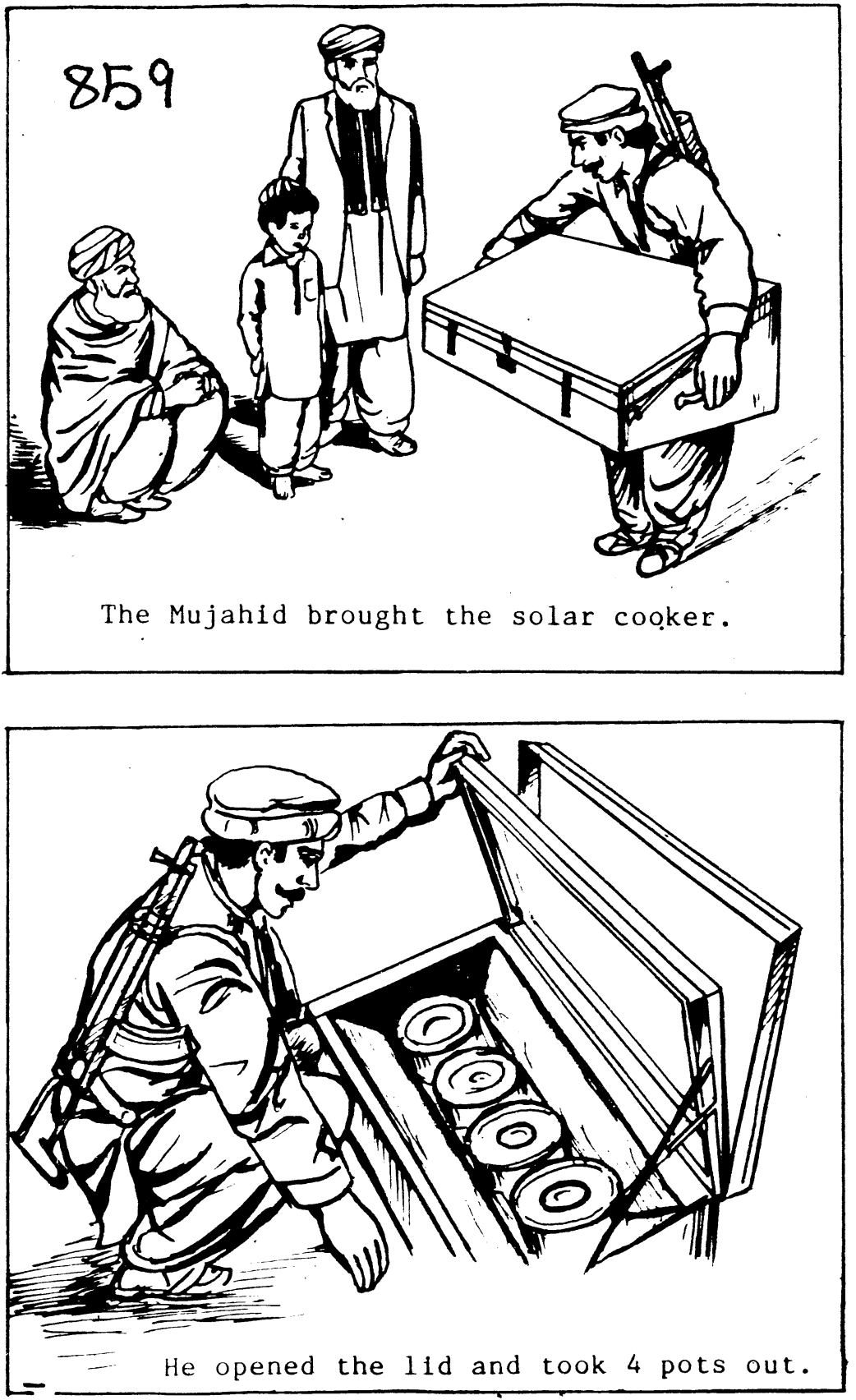

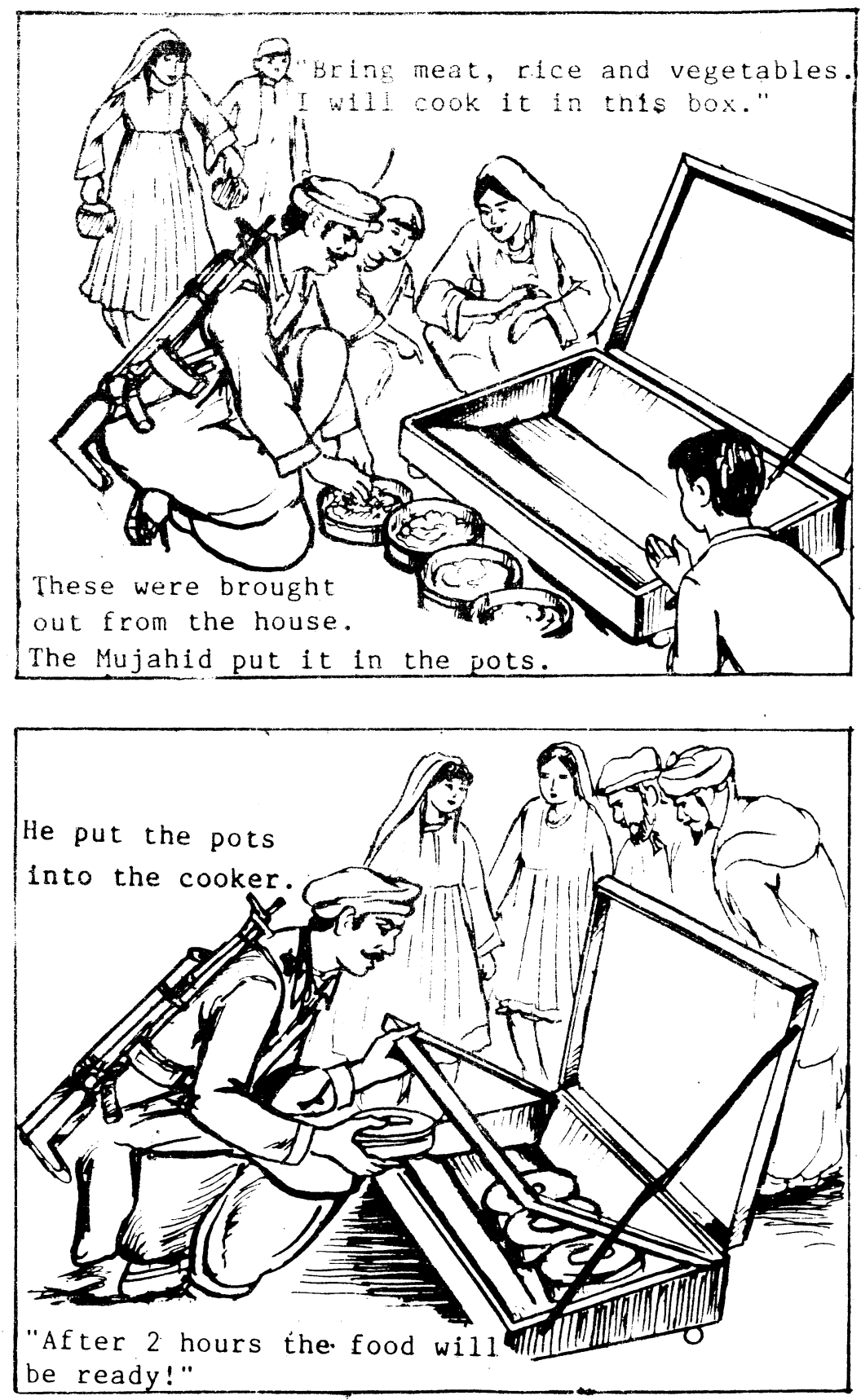

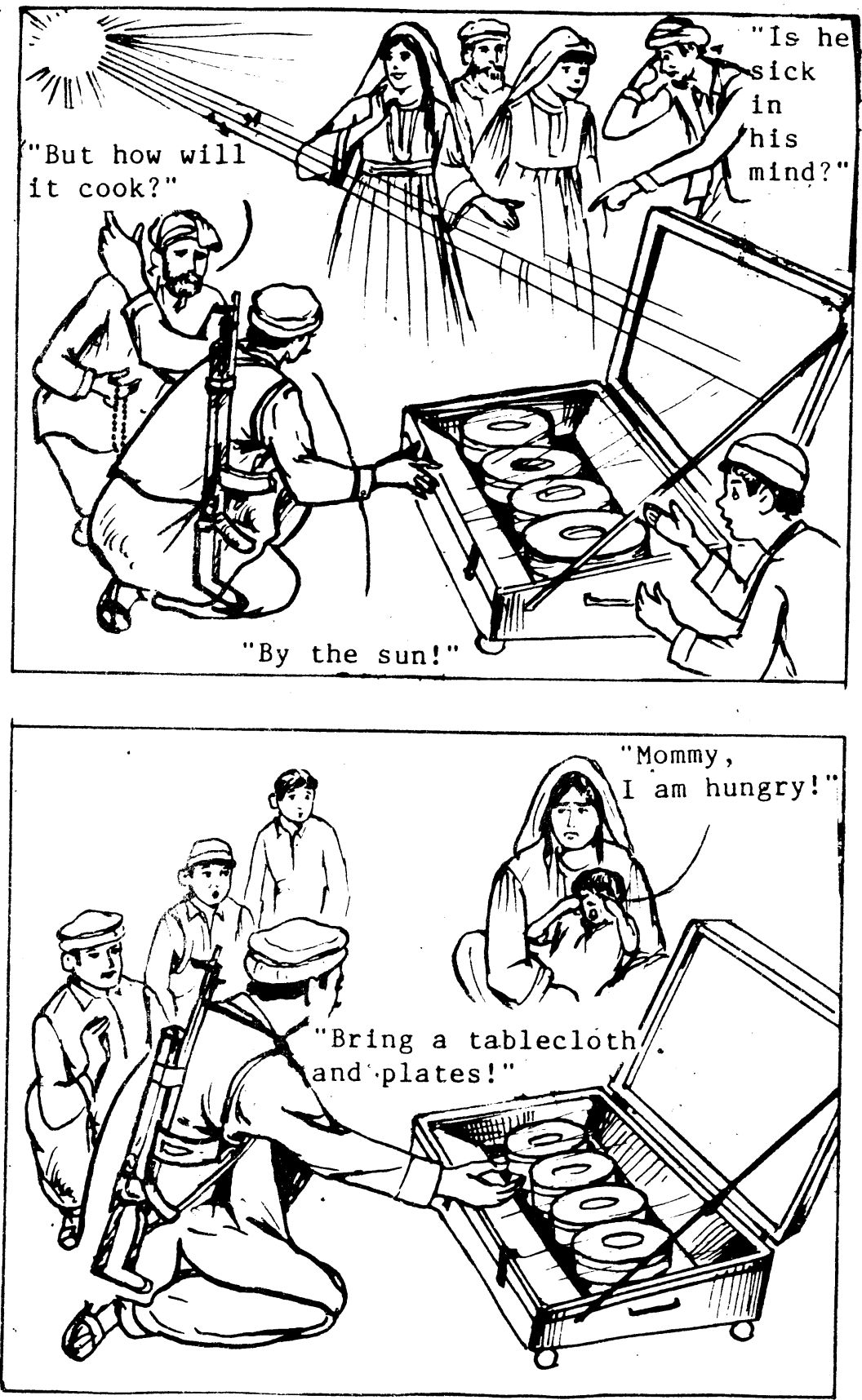
25
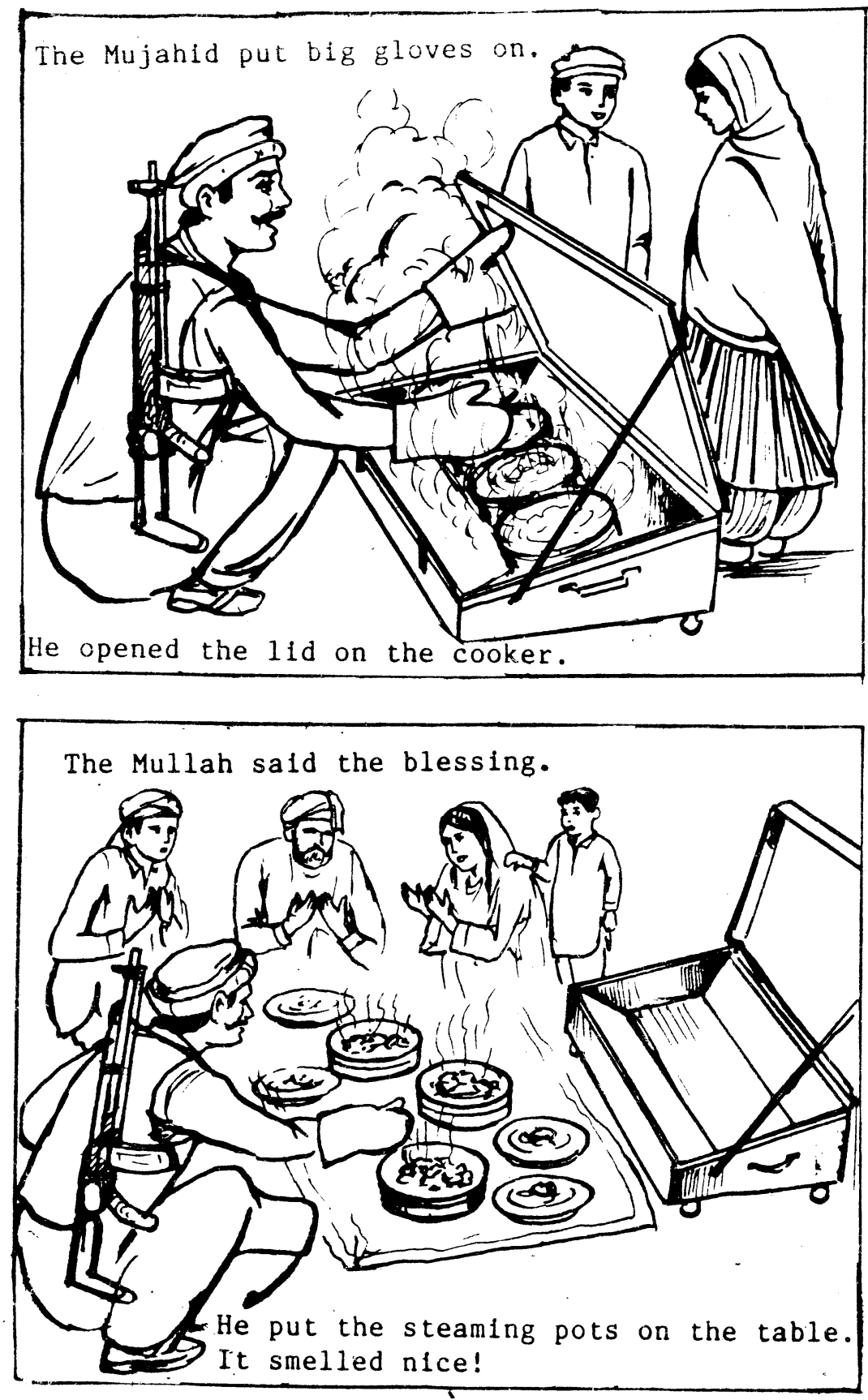
26
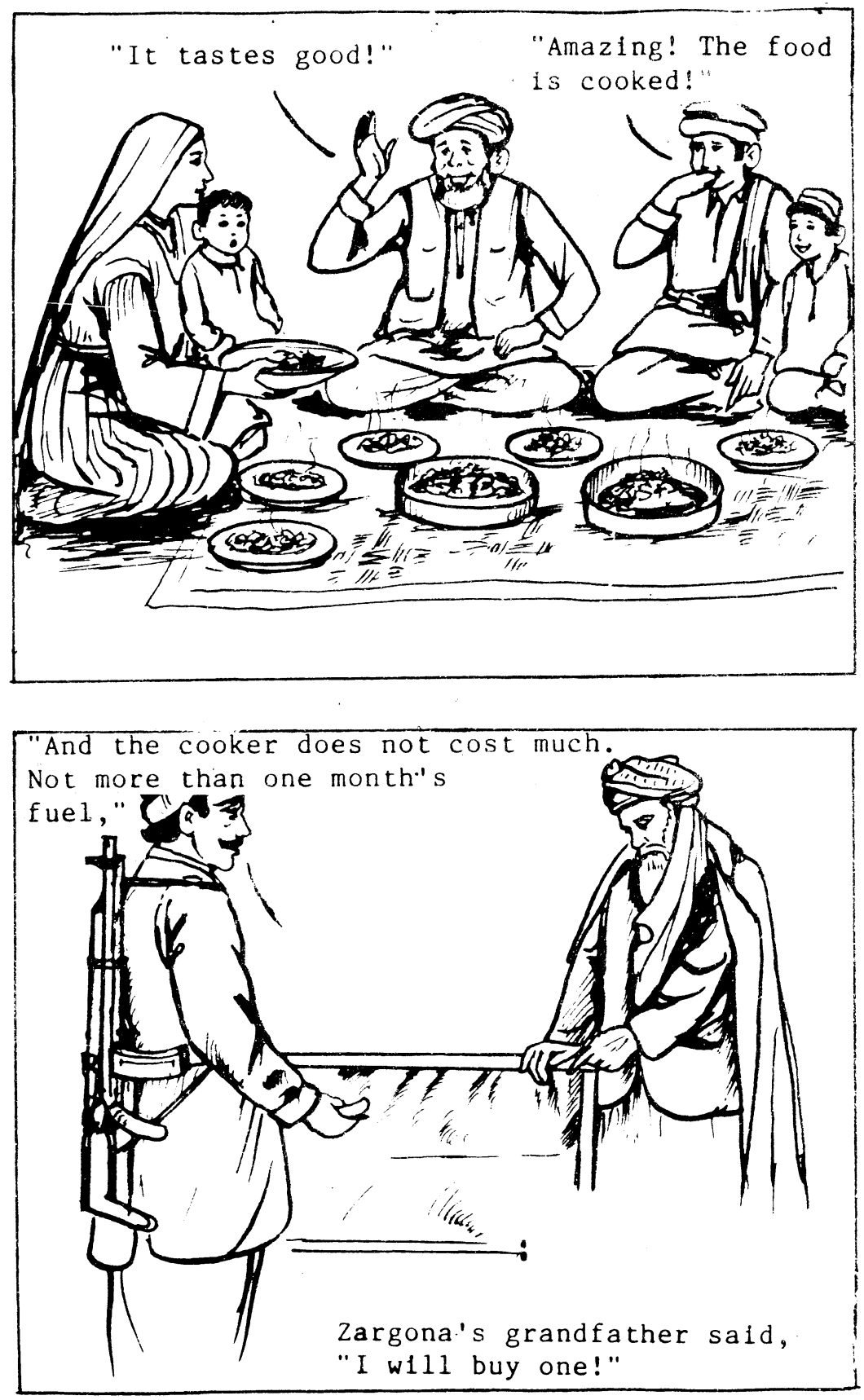
HAVAH
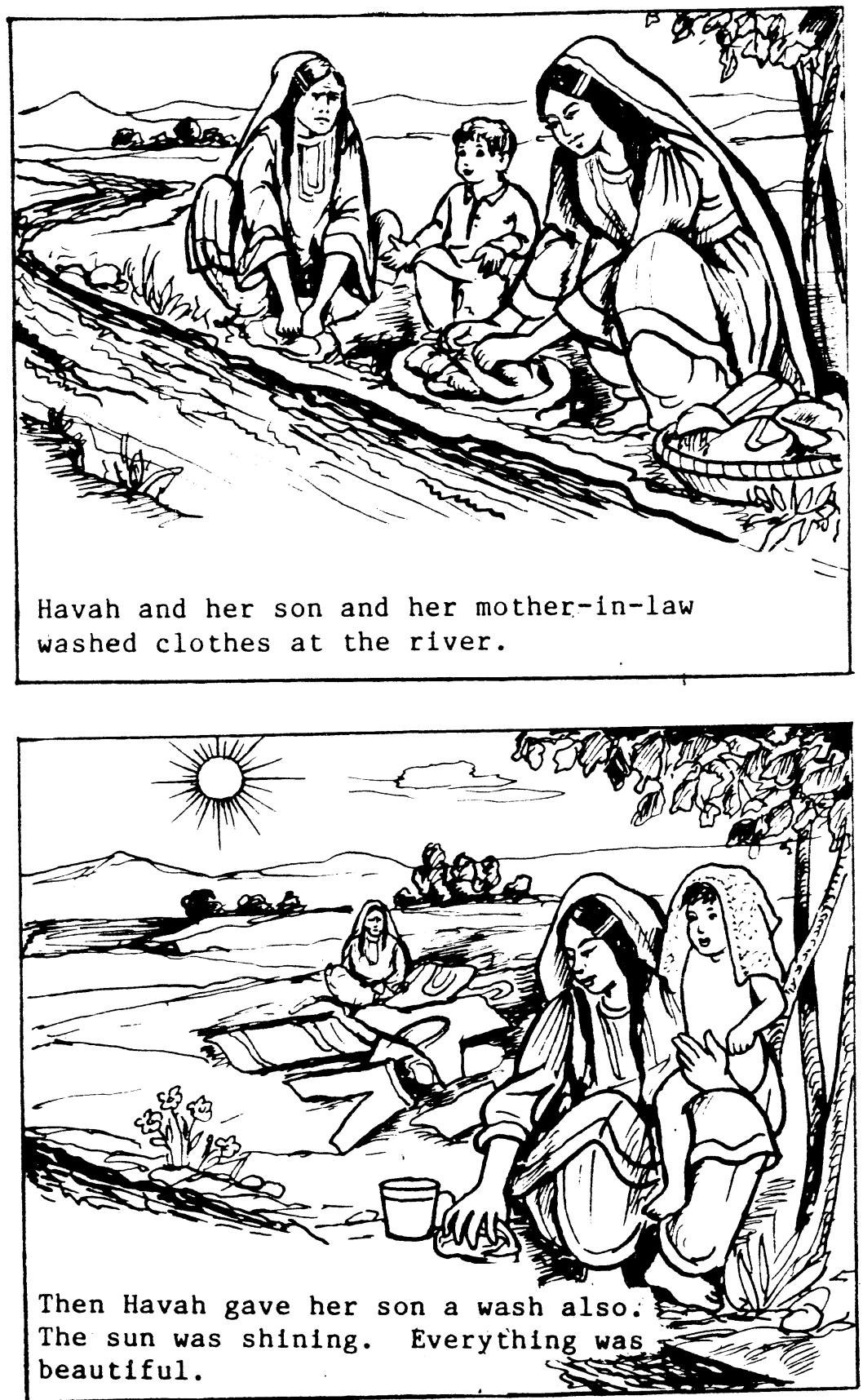
28
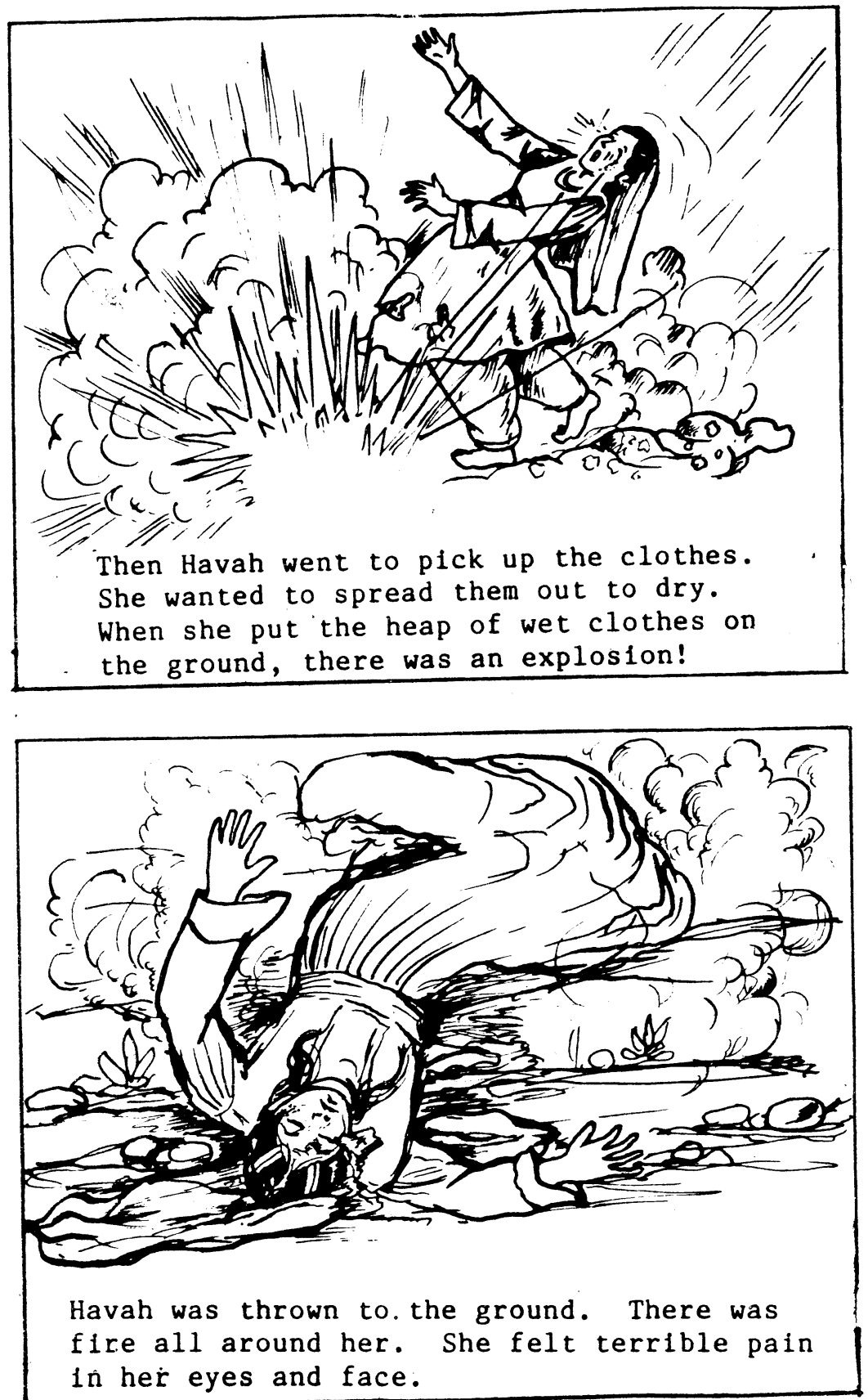

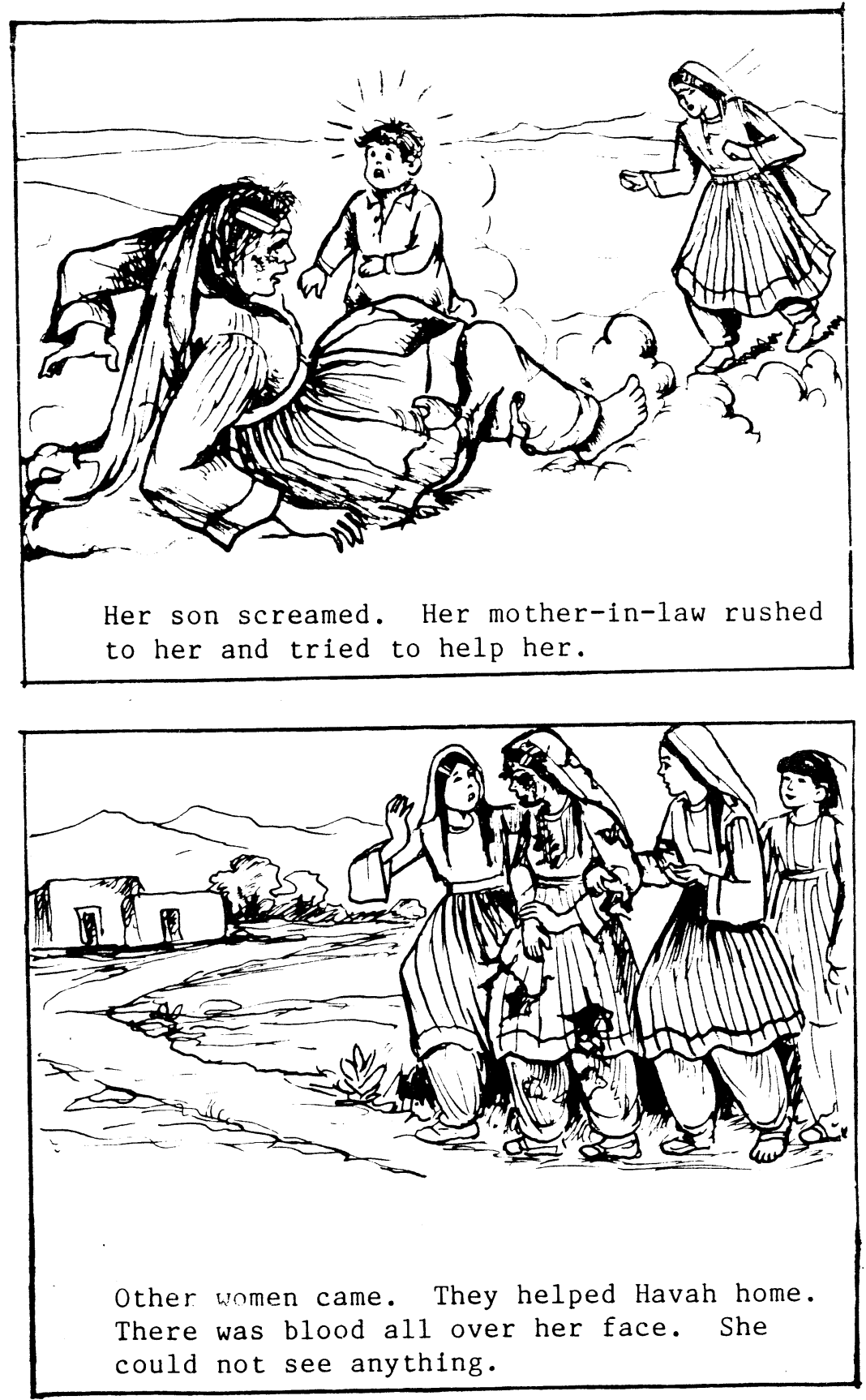

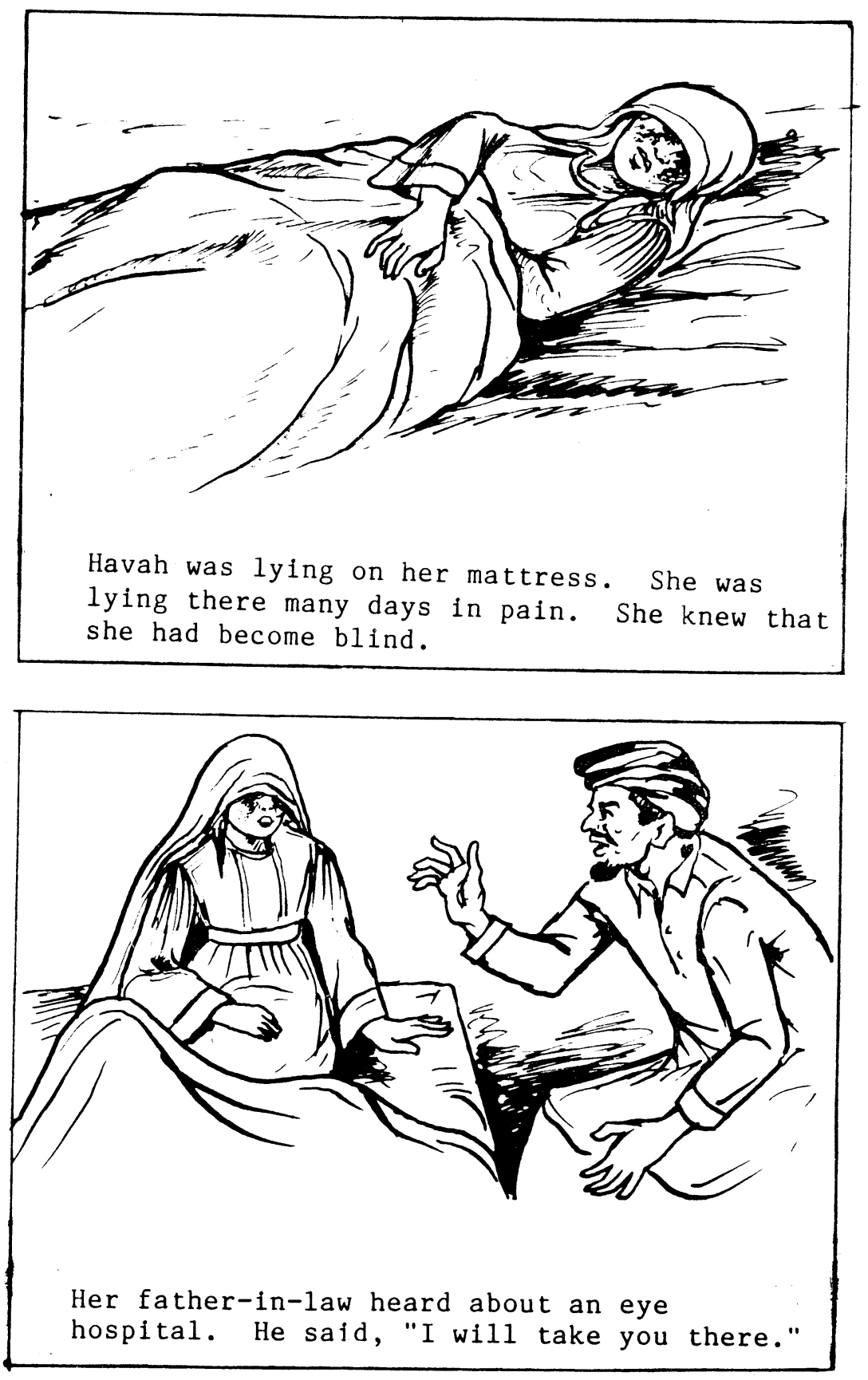

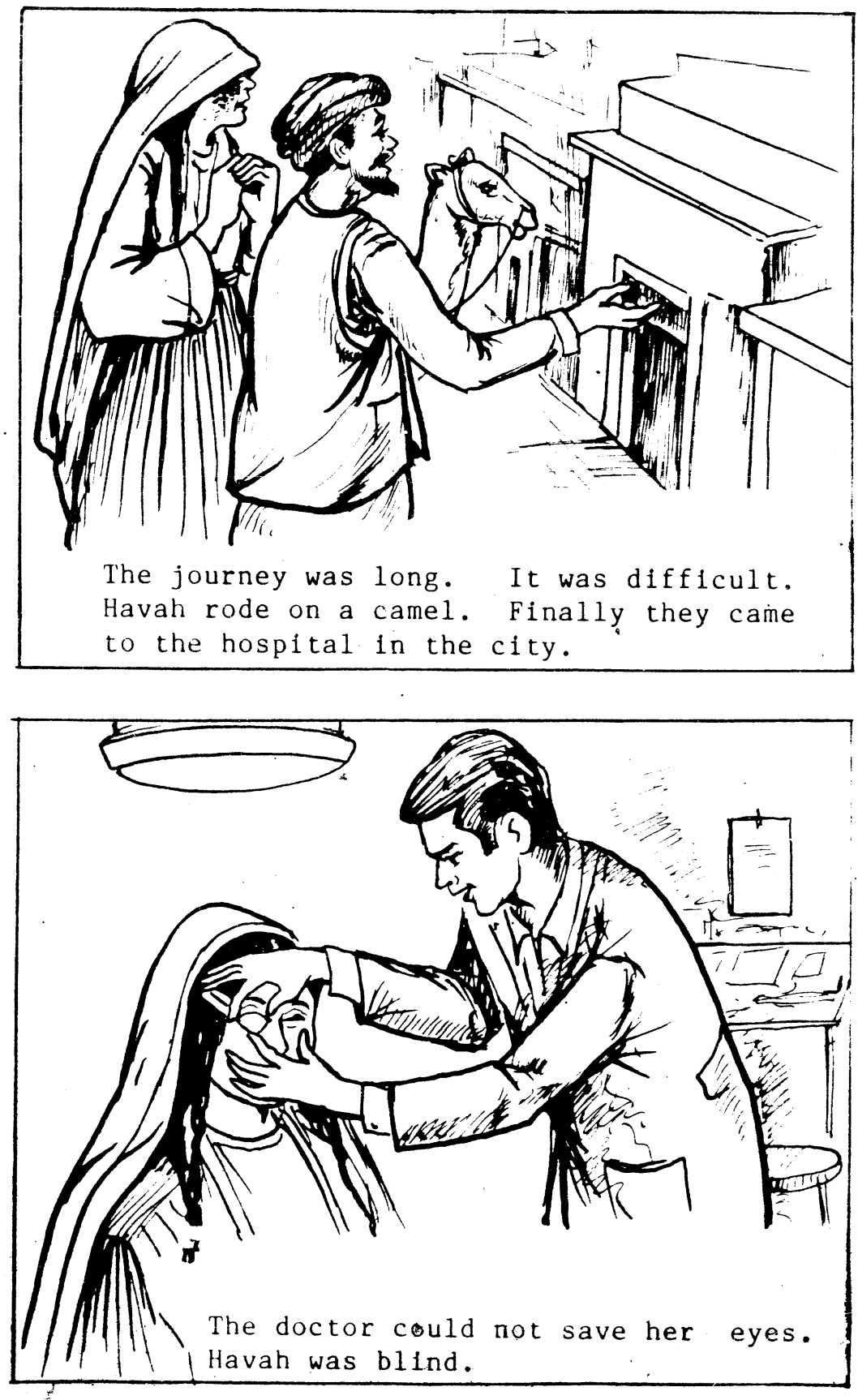

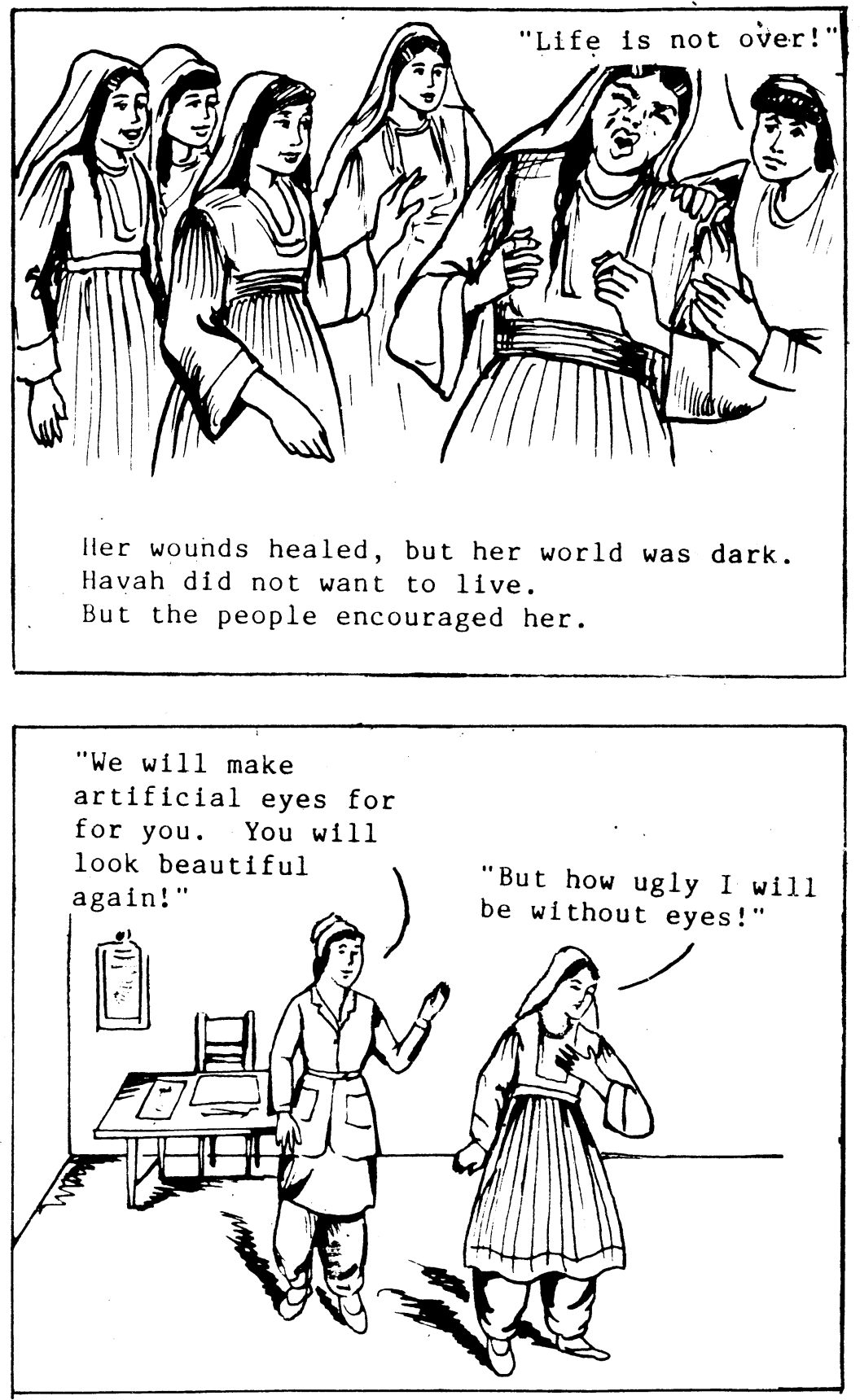
33

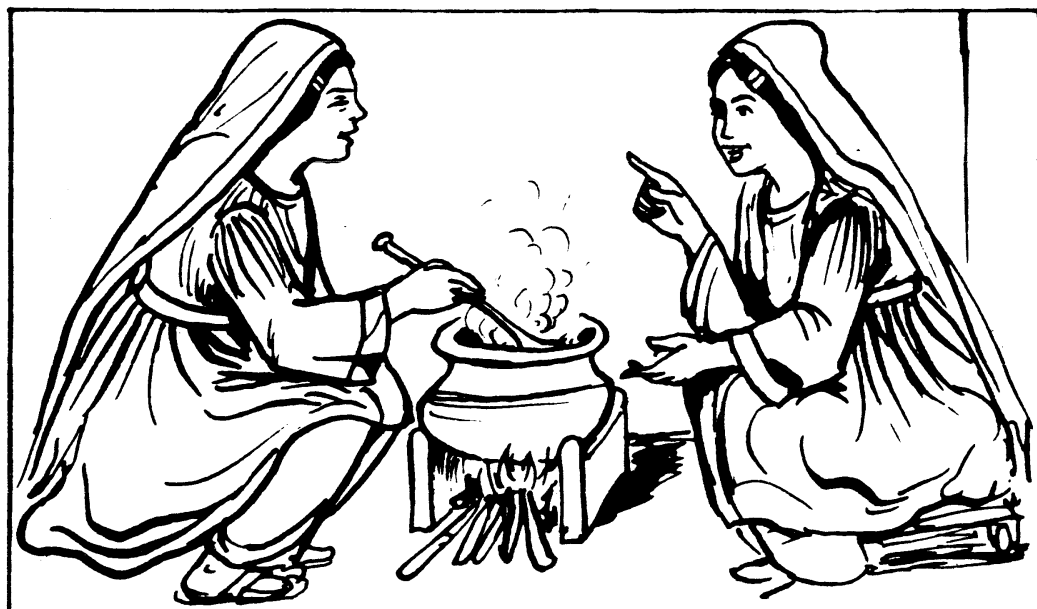

A lady showed Havah how to do things herself. Havah was afraid and hesitant. But she learned more and more.

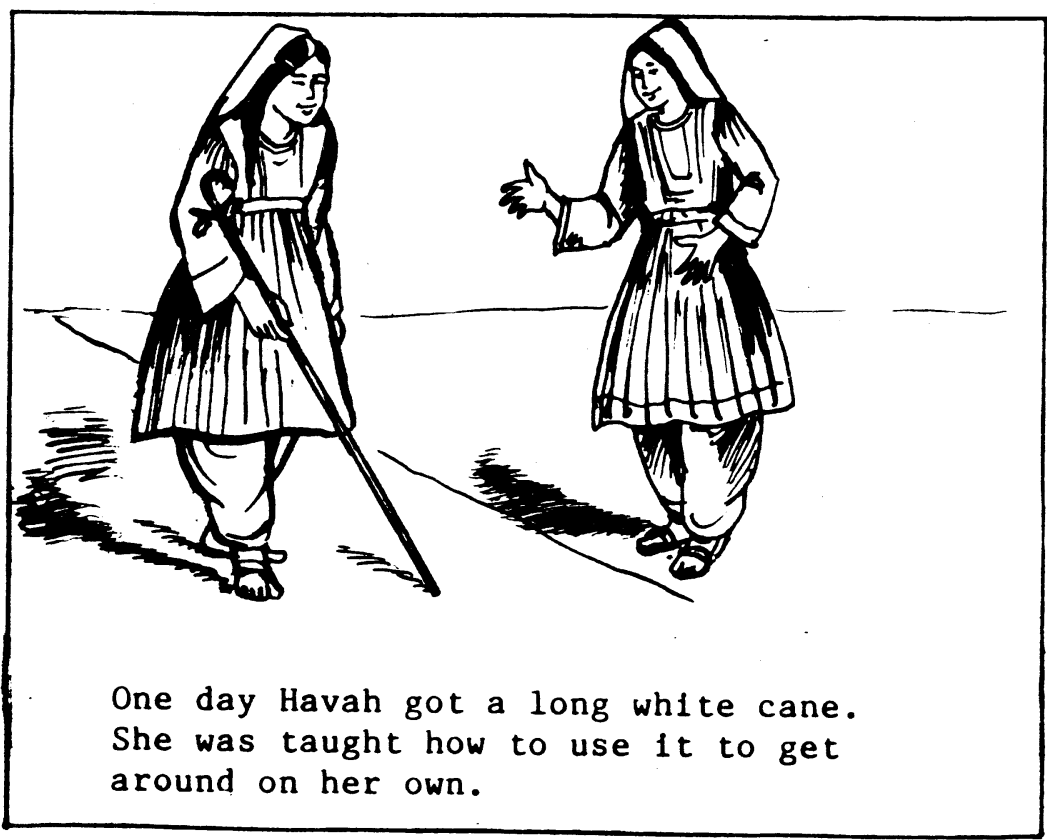



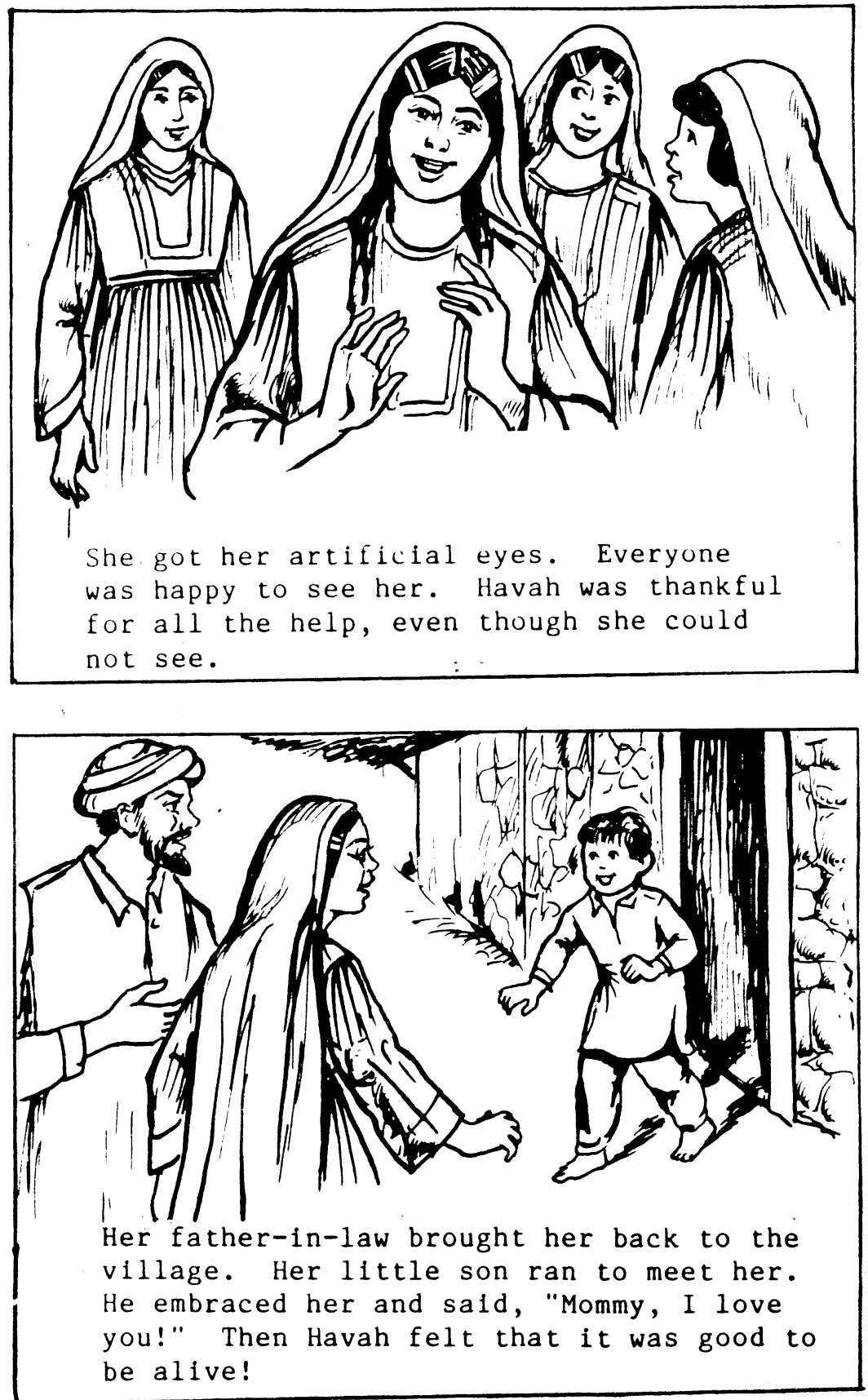

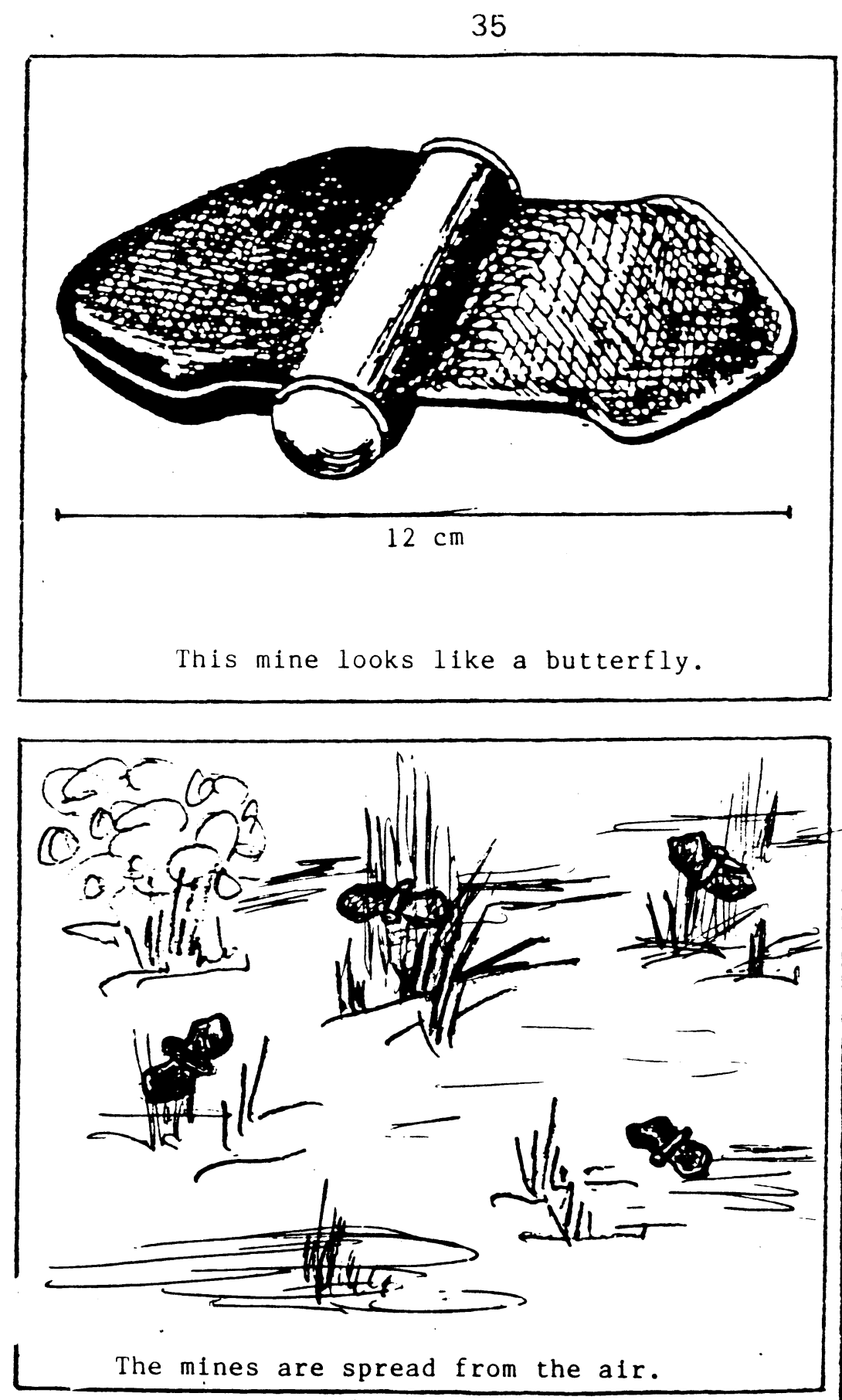


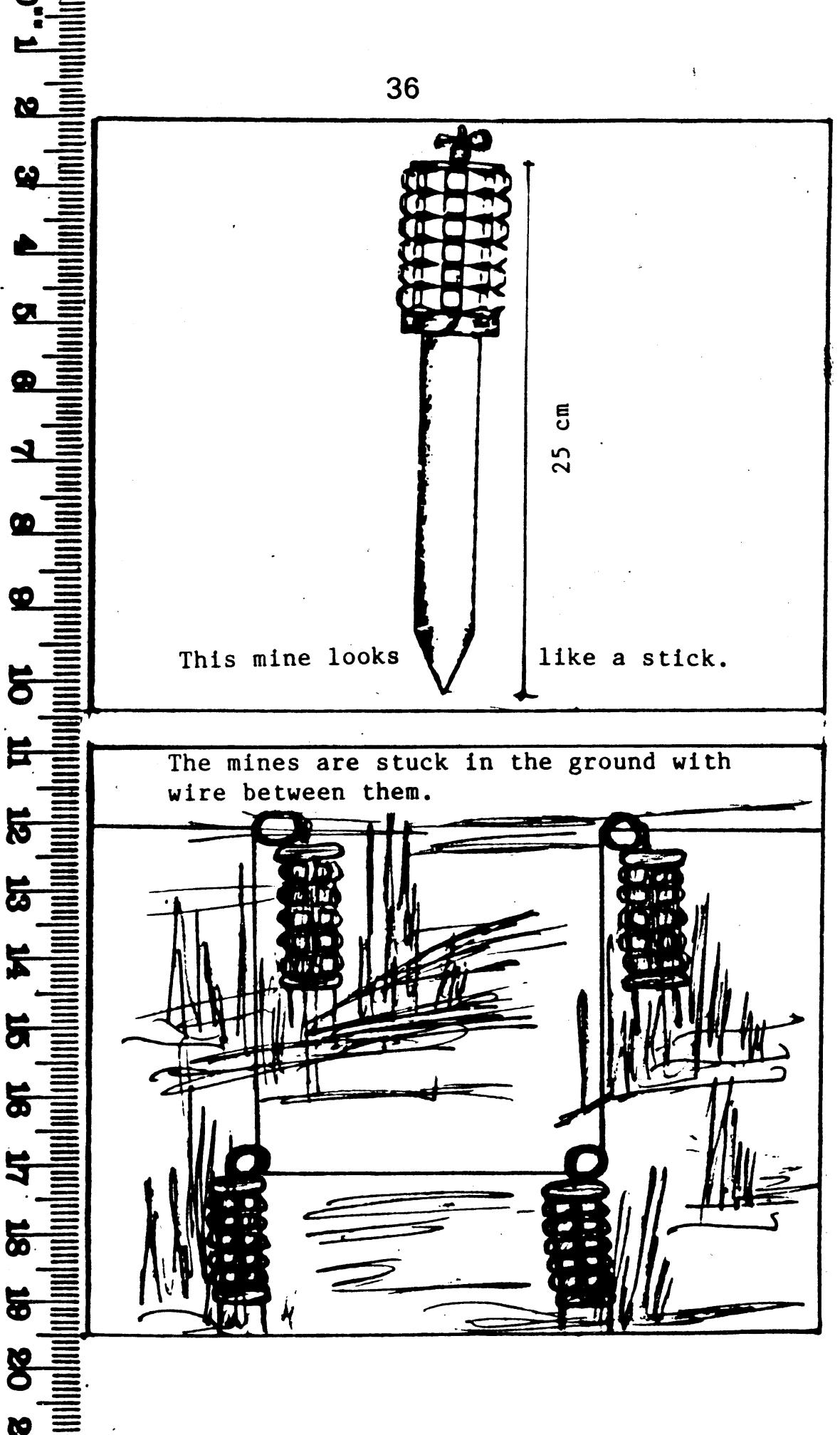



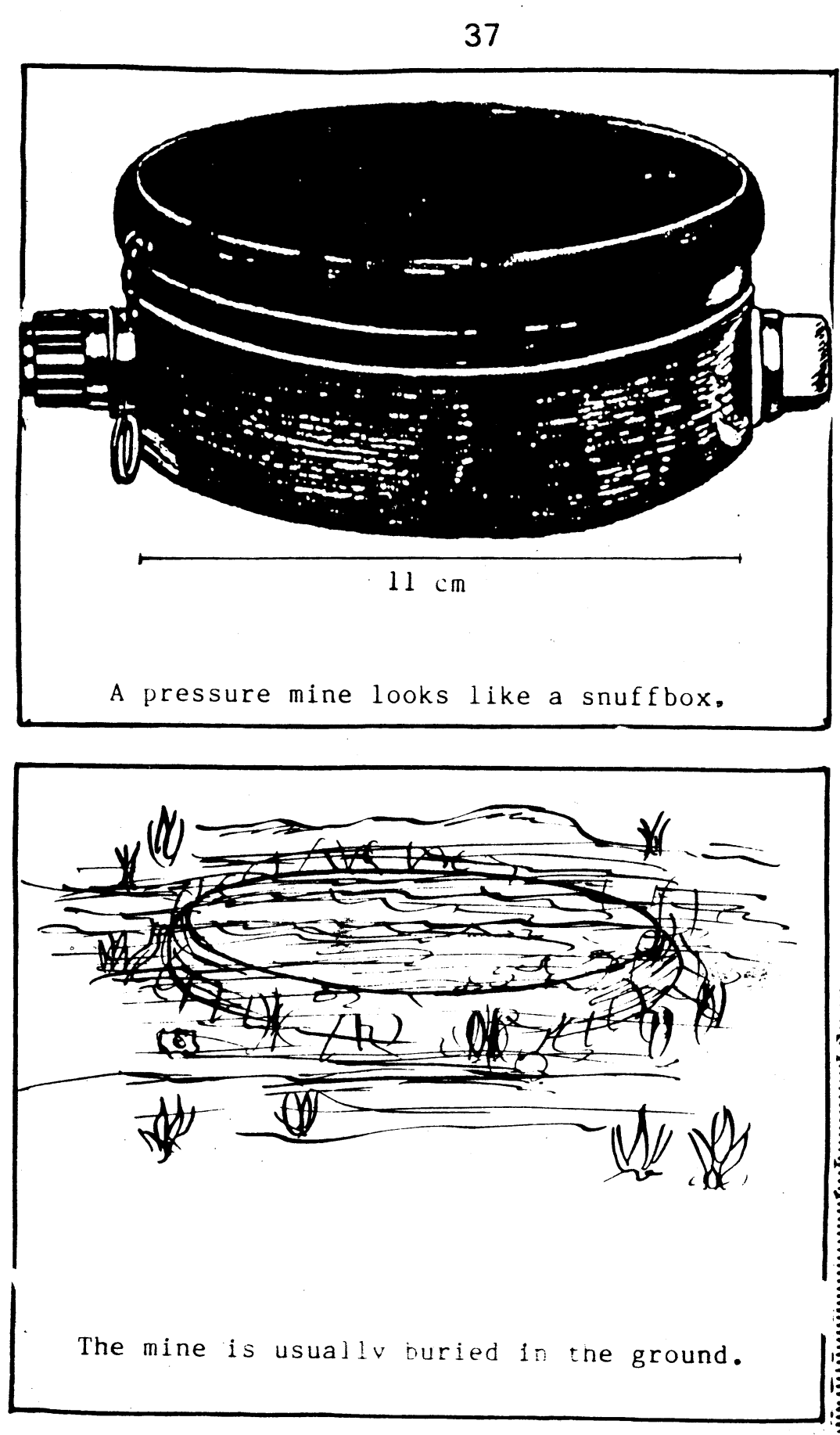


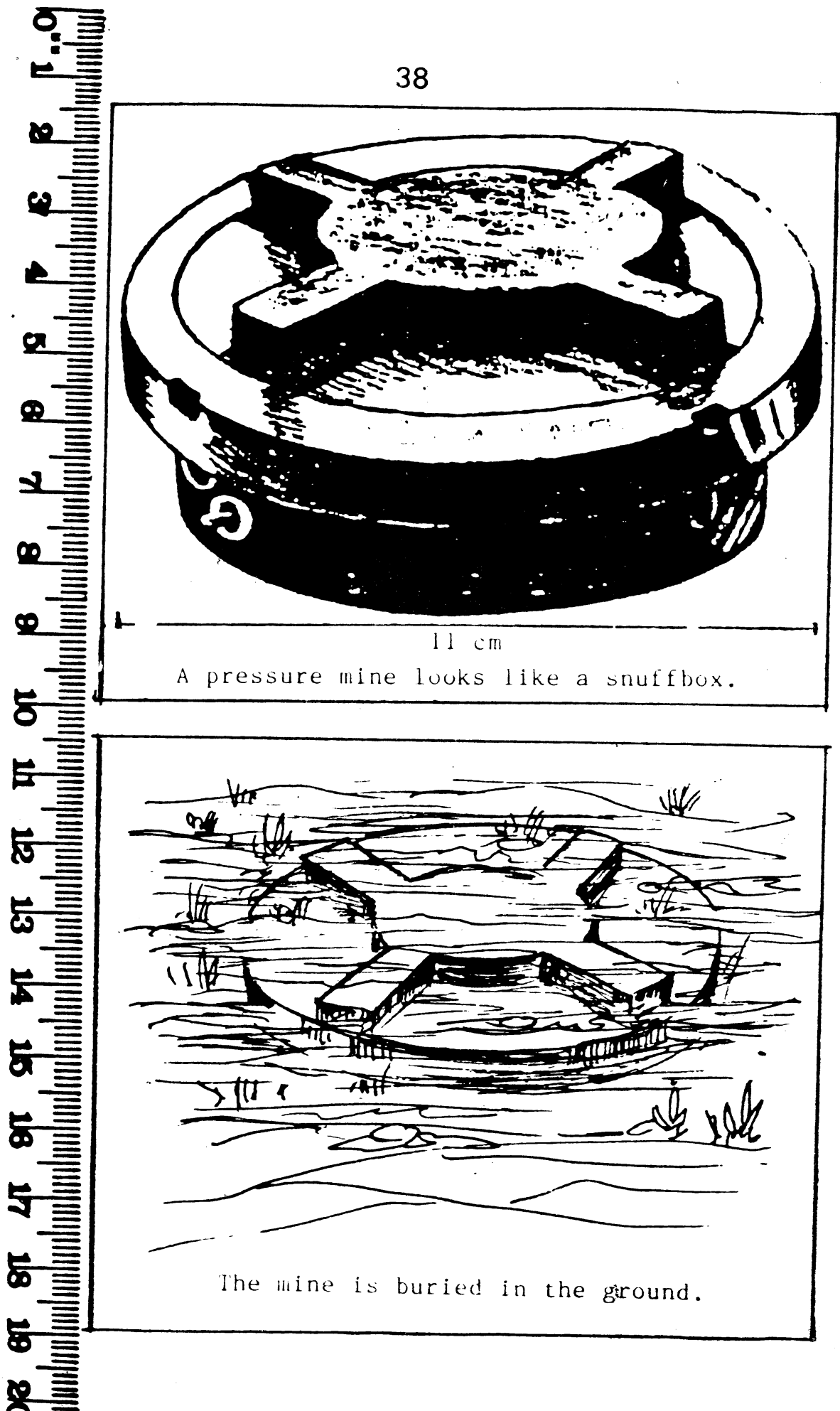




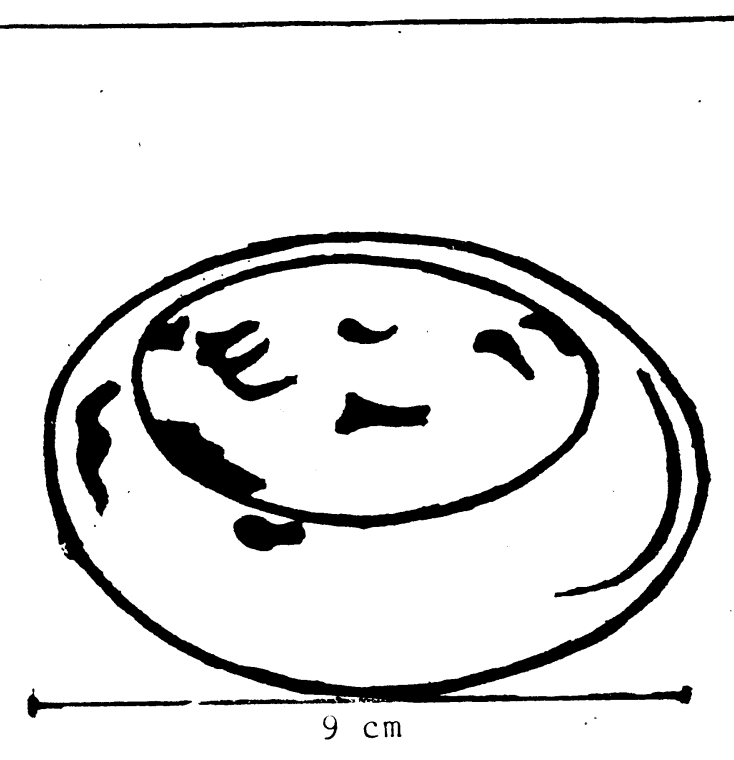

A pressure mine.
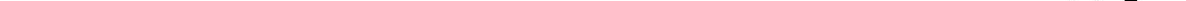

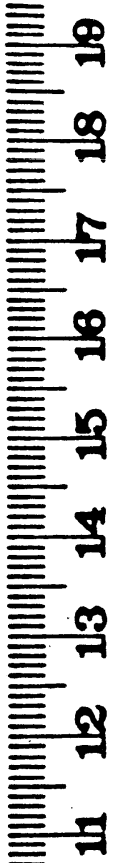




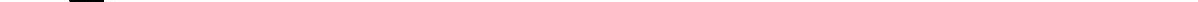


41

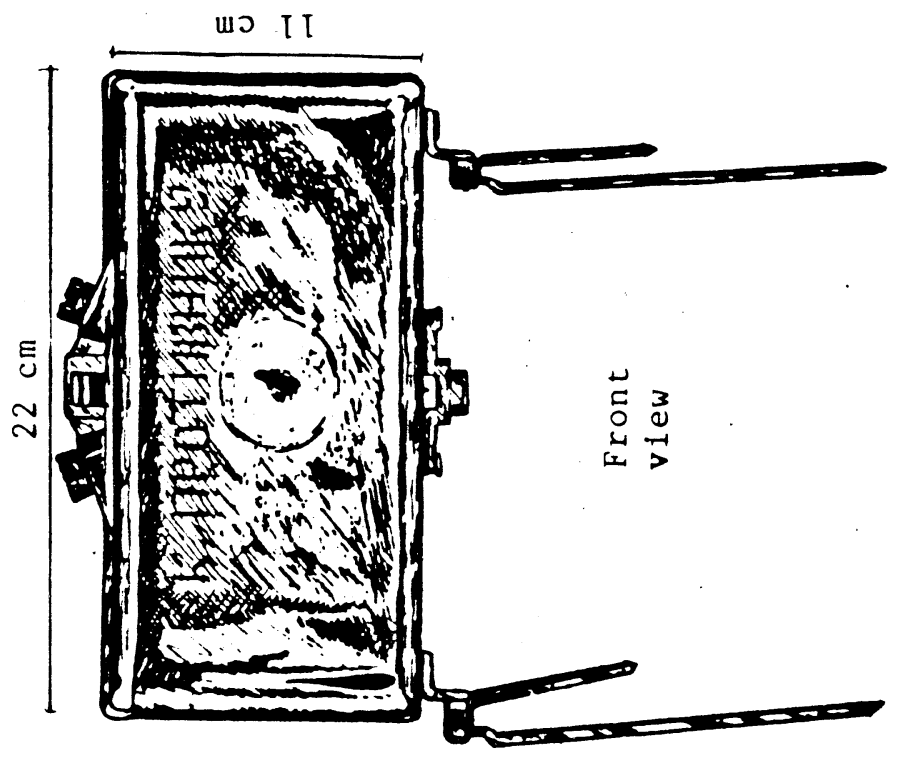




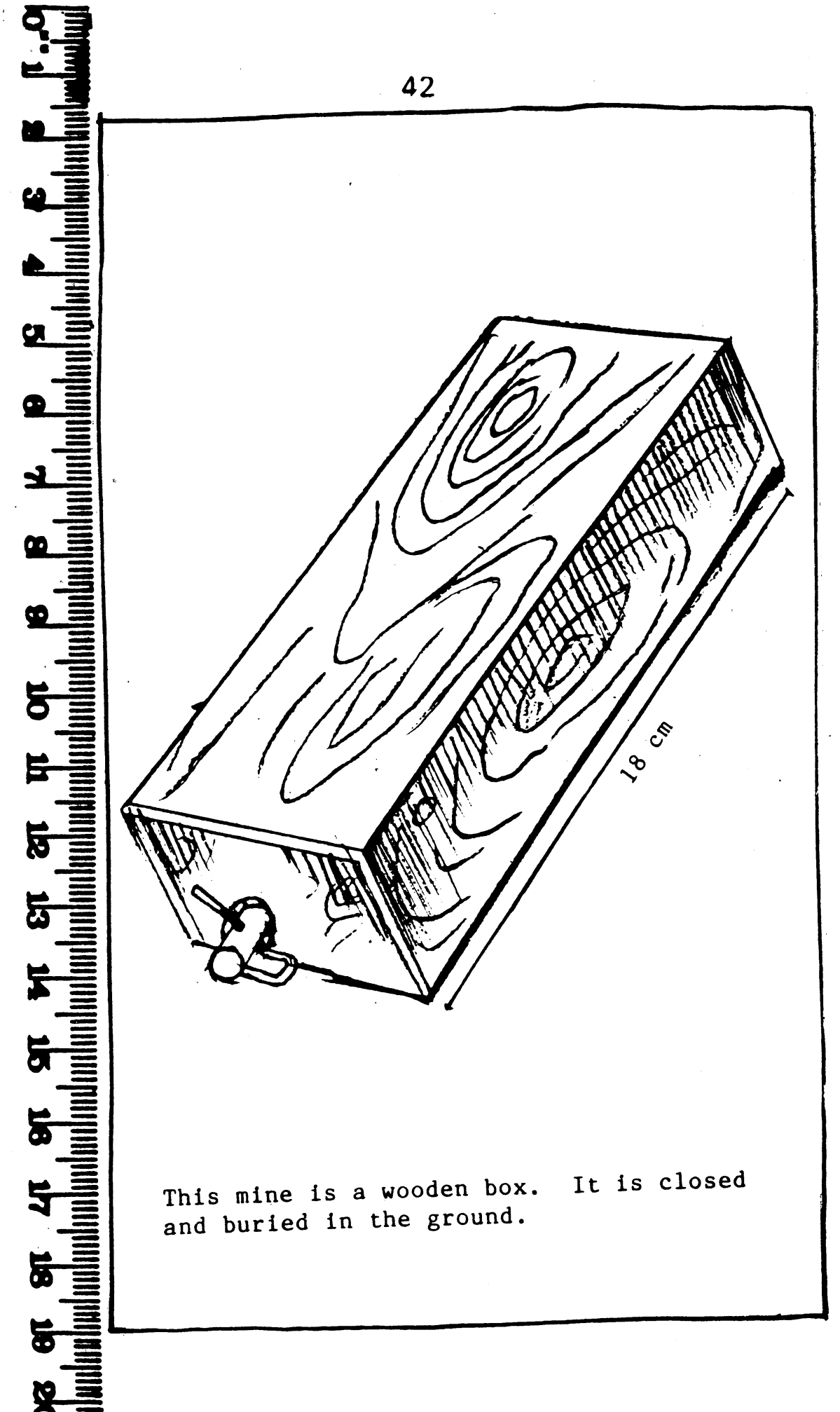




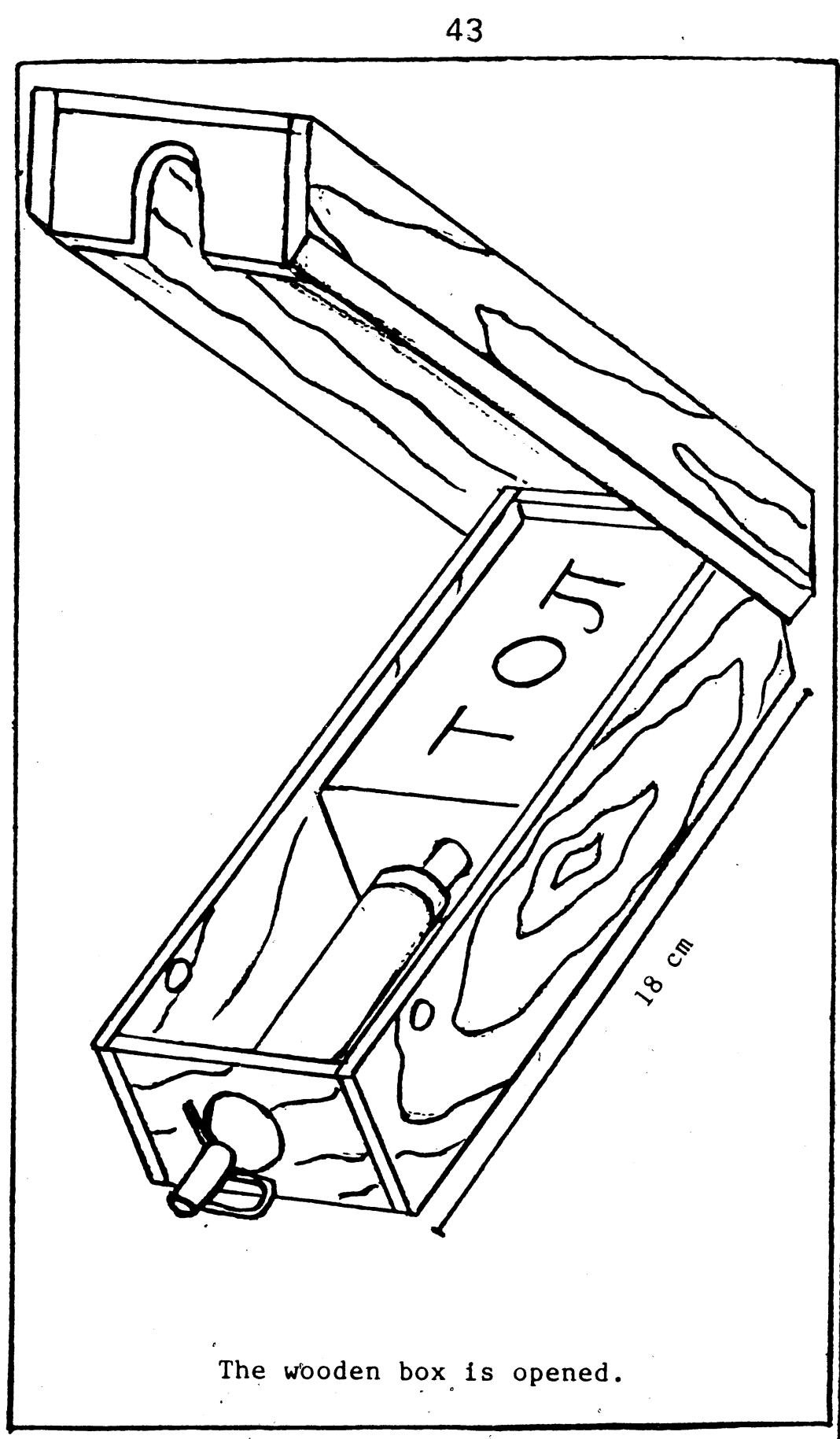




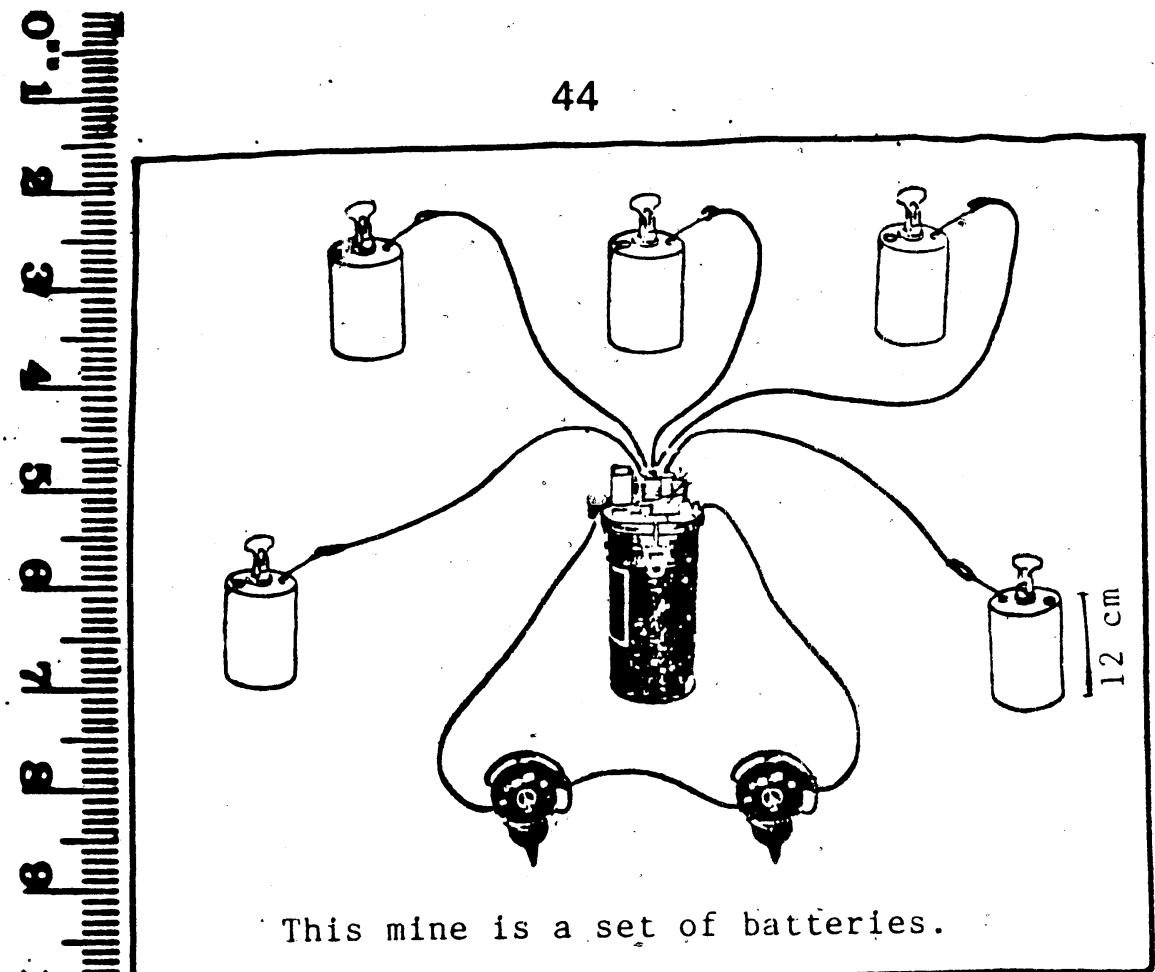

The batteries are buried in the ground and only the wires might be seen. 



\section{6}

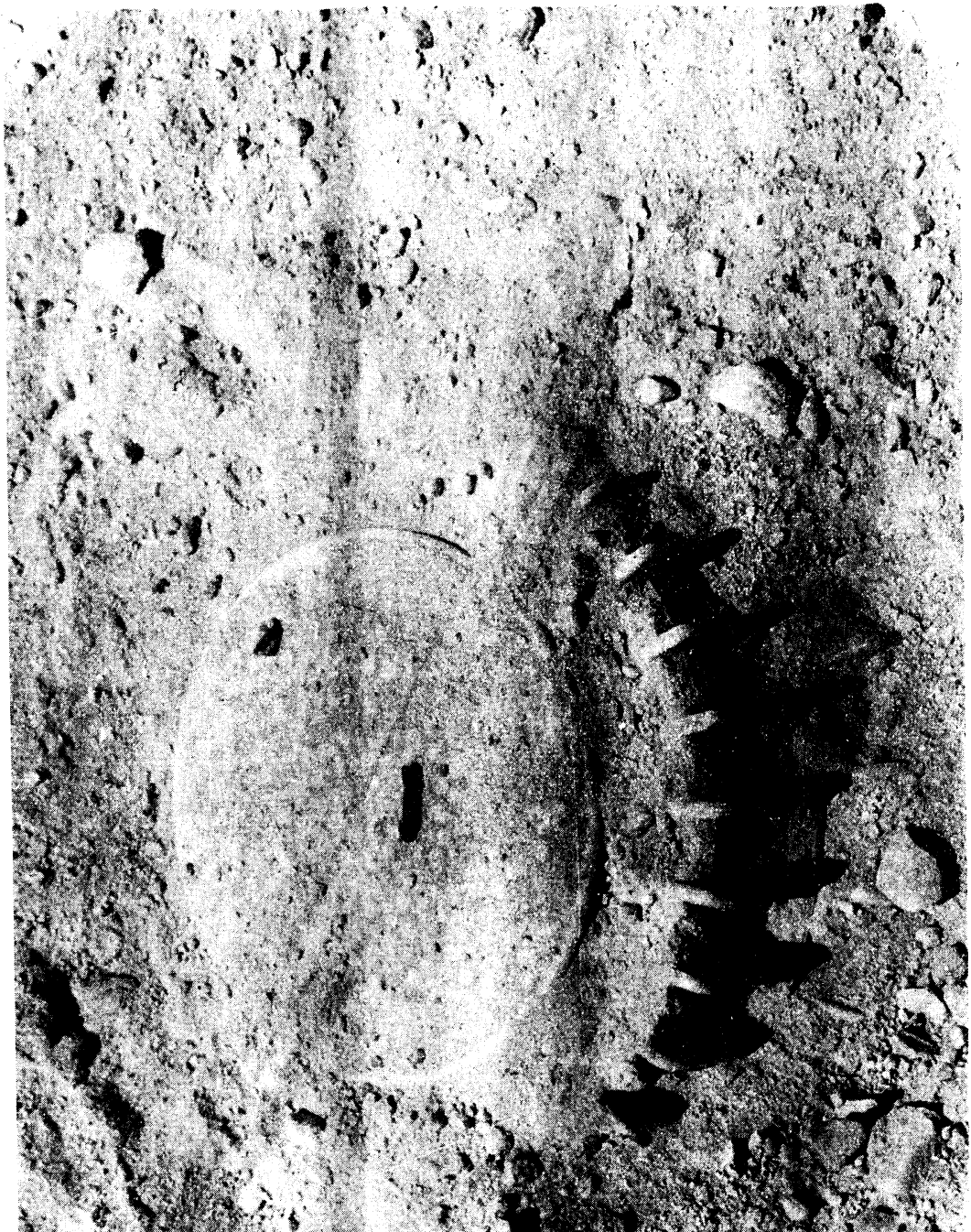

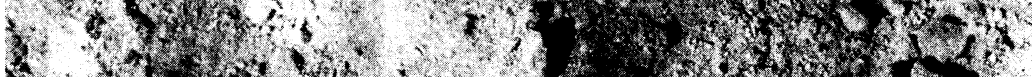

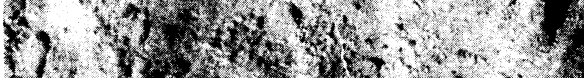

$3 \times 3 \times(x)$

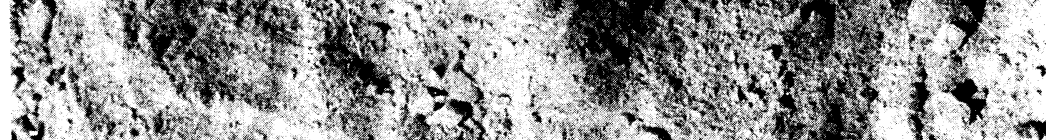

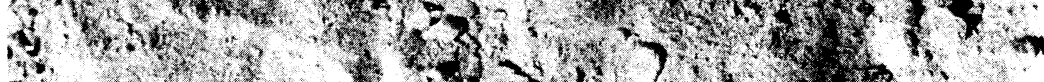

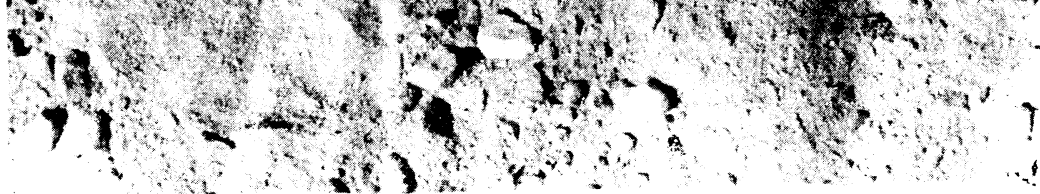

This is an anti-tank mine. The mine is buried in the ground. 


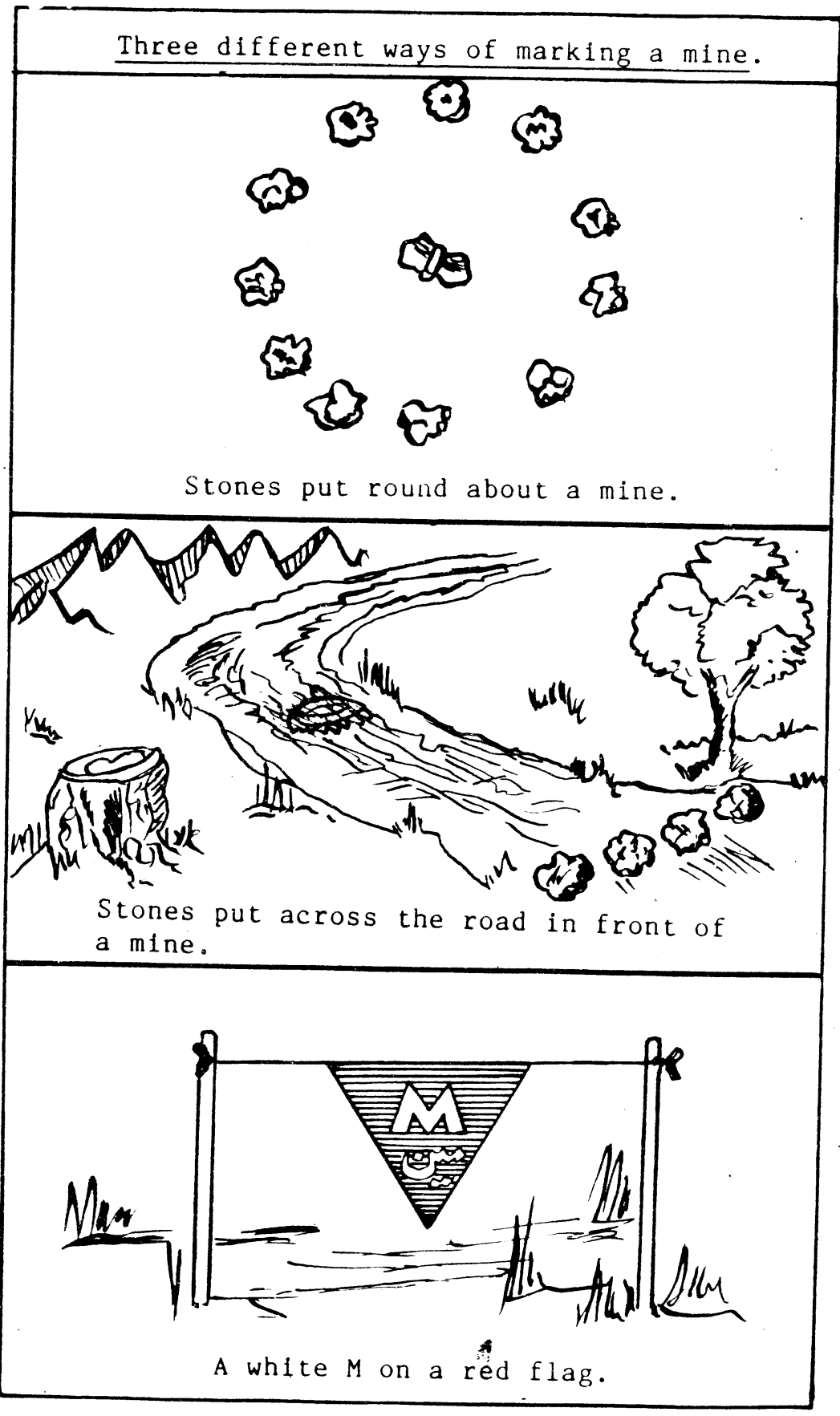




\section{8}

You are reminded again that:

*Never touch anything that is found out of place.

*It could be a mine which is dangerous.

*Mark it with stones or a red flag.

* By doing this you warn others of danger.

$\star$ Tell the village elders what you found and where you found it.

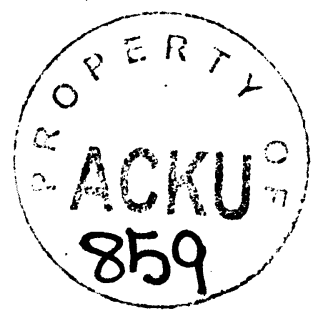




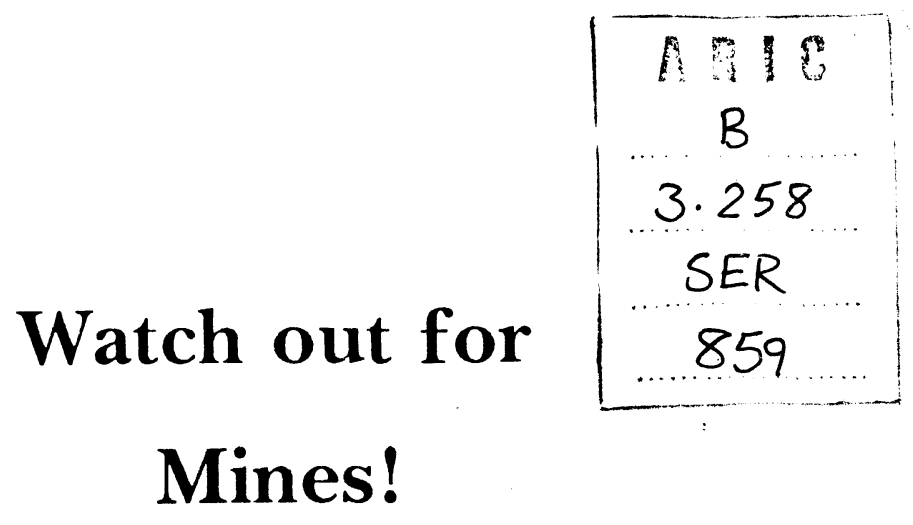

Read in this book about Daoud, Nadir, Mahmood, Zargona and Havah, and see different kinds of mines, and learn to be careful!

Published by:

SERVE

Box 477, Peshawar 